Article

\title{
Antioxidant and Anti-Inflammatory Activities of Cytocompatible Salvia officinalis Extracts: A Comparison between Traditional and Soxhlet Extraction
}

\author{
Sara F. Vieira ${ }^{1,2}\left(\mathbb{D}\right.$, Helena Ferreira ${ }^{1,2}(\mathbb{D}$ and Nuno M. Neves $1,2, *(\mathbb{D}$ \\ 1 3B's Research Group, I3BS-Research Institute on Biomaterials, Biodegradables and Biomimetics, \\ Headquarters of the European Institute of Excellence on Tissue Engineering and Regenerative Medicine, \\ University of Minho, AvePark, Parque de Ciência e Tecnologia, Zona Industrial da Gandra, \\ 4805-017 Barco, Guimarães, Portugal; sara.vieira@i3bs.uminho.pt (S.F.V.); \\ helenaferreira@i3bs.uminho.pt (H.F.) \\ 2 ICVS/3B's-PT Government Associate Laboratory, Braga/Guimarães, Portugal \\ * Correspondence: nuno@i3bs.uminho.pt; Tel.: +35-1253-510-905; Fax: +35-1253-510-909
}

Received: 23 October 2020; Accepted: 18 November 2020; Published: 20 November 2020

check for updates

\begin{abstract}
Chronic inflammation is characterized by an overproduction of several inflammatory mediators (e.g., reactive species and interleukins -IL) that play a central role in numerous diseases. The available therapies are often associated with serious side effects and, consequently, the need for safer drugs is of utmost importance. A plant traditionally used in the treatment of inflammatory conditions is Salvia officinalis. Therefore, conventional maceration and infusion of its leaves were performed to obtain hydroethanolic (HE-T) and aqueous extracts (AE-T), respectively. Their efficacy was compared to soxhlet extracts, namely aqueous (AE-S), hydroethanolic (HE-S), and ethanolic extracts (EE-S). Thin-layer chromatography demonstrated the presence of rosmarinic acid, carnosol, and/or carnosic acid in the different extracts. Generally, soxhlet provided extracts with higher antioxidant activities than traditional extraction. Moreover, under an inflammatory scenario, EE-S were the most effective, followed by HE-S, HE-T, AE-T, and AE-S, in the reduction of IL- 6 and TNF- $\alpha$ production. Interestingly, the extracts presented higher or similar anti-inflammatory activity than diclofenac, salicylic acid, and celecoxib. In conclusion, the extraction method and the solvents of extraction influenced the antioxidant activity, but mainly the anti-inflammatory activity of the extracts. Therefore, this natural resource can enable the development of effective treatments for oxidative stress and inflammatory diseases.
\end{abstract}

Keywords: Salvia officinalis; traditional extraction; soxhlet extraction; antioxidant activity; reactive oxygen and nitrogen species; anti-inflammatory activity; cytocompatibility

\section{Introduction}

Inflammation is essential for human life, leading to the elimination of noxious stimuli and restoration of tissue homeostasis [1]. However, if the inflammatory response is prolonged, continuous recruitment of inflammatory cells and overproduction of reactive oxygen and nitrogen species (ROS/RNS) are observed, inducing tissue damage [1-3].

High amounts of ROS/RNS (e.g., superoxide radical anion $-\mathrm{O}_{2}^{\bullet-}$ - and nitric oxide - $\mathrm{NO}$ ) are produced by activated immune cells (e.g., neutrophils and macrophages) to protect the organism against, for instance, bacteria or intracellular parasites [4,5]. ROS/RNS can also activate several essential inflammatory pathways, which will result in the release of several proinflammatory cytokines (e.g., 
interleukin -IL-6, tumor necrosis factor -TNF- $\alpha$ ) and chemokines (e.g., IL-8) with the ability to recruit more immune cells to the site of inflammation [6,7]. IL-6 is a particularly important mediator of the acute phase response, inducing fever, stimulating the production of neutrophils in the bone marrow, and supporting the growth and differentiation of $B$ cells [8]. Another cytokine with an important role in the pathogenesis of inflammatory conditions is TNF- $\alpha$ to regulate cell growth and proliferation, the release of adhesion molecules, and the expression of inflammatory mediators [9].

Unfortunately, high amounts of ROS/RNS and proinflammatory mediators in the tissues/cells can irreversibly damage several biomolecules and/or cells, resulting in the loss of their function and/or death. For instance, ROS/RNS can induce lipid peroxidation, leading to the cells' membrane damage, culminating with their death [10]. Consequently, a dysregulated inflammatory response can lead to several diseases, such as rheumatoid arthritis, osteoarthritis, cardiovascular diseases, neurodegenerative diseases, or cancer [7,11-13]. Therefore, the administration of antioxidant and/or anti-inflammatory compounds is crucial to stop the unregulated inflammatory scenario. Currently available therapies are based on nonsteroidal anti-inflammatory drugs (NSAIDs, e.g., diclofenac, salicylic acid, and celecoxib), corticosteroids (e.g., dexamethasone and betamethasone), conventional disease-modifying anti-rheumatic drugs (DMARDs, e.g., methotrexate), and biological agents (e.g., anti-TNF- $\alpha$ and anti-IL-1 $\beta$ antibodies) [14-16]. These therapeutic agents, however, are often associated with several serious side effects [17-23]. Therefore, the need to discover new, safe, and effective anti-inflammatory drugs is of utmost importance.

Plants have been the basis of traditional medicine in many cultures for thousands of years. Even nowadays, plants, being a rich source of bioactive molecules, are widely used by the world's population to treat several diseases [24]. Moreover, more than one hundred compounds in clinical use are derived from plants [25-27]. Some examples of plant-derived drugs widely prescribed include morphine (analgesic, Papaver somniferum), digitoxin (cardiotonic, Digitalis purpurea), and vincristine (anti-cancer, Catharanthus roseus). Indeed, there is an increasing interest in drug discovery from plant origin [28,29], mainly due to the reduction of the costs associated with the development of new drugs [30,31].

Salvia officinalis (Lamiaceae family), commonly known as garden sage, Dalmatian sage, or common sage, is widely used in traditional medicine. An infusion of dried sage leaves with boiling water (sage tea) has been traditionally used to treat mouth, throat, and bronchial inflammations, as well as coughs and stomach pain [32,33]. Sage leaves can also be directly applied for cold sores, gum disease, sore mouth, throat or tongue, and swollen tonsils. Particularly in inflammatory diseases, different extracts of $S$. officinalis demonstrated the ability to reduce IL-6 and IL-8 production [34], inhibit ${ }^{\bullet} \mathrm{NO}$ generation [35], increase the number of antioxidant enzymes [36], and reduce leukocyte infiltration, plasmatic extravasation, and edema [37]. However, the properties of tea and tinctures of S. officinalis on the behavior of human macrophages have not been reported in detail, in spite of its common use in inflammation treatment. In this work, traditional extraction, namely maceration and infusion, was performed to obtain aqueous (AE-T) and hydroethanolic extracts (HE-T), respectively. To increase the yield of extraction, aqueous (AE-S), hydroethanolic (HE-S), and ethanolic extracts (EE-S) were prepared using a soxhlet. After extraction, the total phenol and flavonoid content (TPC and TFC, respectively) were measured, and the composition of S. officinalis extracts was analyzed by thin-layer chromatography (TLC). The antiradical activity of $S$. officinalis extracts against 2,2-diphenyl-1-picrylhydrazyl ( $\mathrm{DDPH}^{\bullet}$ ) and 2,2'-azino-bis(3-ethylbenzothiazoline-6-sulfonic acid) diammonium salt $\left(\mathrm{ABTS}^{\bullet+}\right.$ ) was also evaluated, as well as their antioxidant activity against the most powerful ROS/RNS, namely ROO ${ }^{\bullet} \mathrm{O}_{2}{ }^{\bullet-}$, and ${ }^{\bullet} \mathrm{NO}$. The reducing power (RP) of the five $S$. officinalis extracts was also investigated. The cytotoxicity of $S$. officinalis extracts was evaluated using the L929 cell line, according to ISO 10993-5:2009 [38]. Moreover, their capacity to stimulate or inhibit the production of two proinflammatory cytokines with a crucial role in the inflammatory response, IL- 6 and TNF- $\alpha$, was investigated using nonstimulated or LPS-stimulated macrophages (THP-1 cell line), respectively. For all cellular studies, the metabolic activity, the DNA concentration, the total protein content, and the cells' morphology were analyzed. 
To the best of our knowledge, this is the first study that exhaustively compares the efficiency of several S. officinalis extracts obtained from soxhlet and traditional extraction regarding their cytocompatibility and antioxidant and anti-inflammatory activities.

\section{Materials and Methods}

\subsection{Reagents}

An aluminum TLC plate, silica gel coated with fluorescent indicator F254 $(20 \times 20 \mathrm{~cm})$, chloroform, ethyl acetate, acetic acid, ethanol, sodium carbonate $\left(\mathrm{Na}_{2} \mathrm{CO}_{3}\right)$, Folin-Ciocalteu's phenol reagent, gallic acid, aluminum chloride, rutin, $\mathrm{DPPH}^{\bullet}, \mathrm{ABTS}^{\bullet+}$, potassium phosphate dibasic, potassium phosphate monobasic, fluorescein sodium salt, 2,2'-azobis(2-methylpropionamidine) dihydrochloride (AAPH), sodium nitroprusside dihydrate (SNP), sulfanilamide (SA), N-(1-Naphthyl)ethylenediamine dihydrochloride (NED), phosphoric acid, phosphate-buffered saline (PBS), $\beta$-Nicotinamide adenine dinucleotide (NADH), nitrotetrazolium blue chloride (NBT), phenazine methosulfate (PMS), sodium phosphate dibasic, sodium phosphate monobasic, potassium ferricyanide (III), trichloroacetic acid and ferric chloride (III), low-glucose Dulbecco's modified eagle's medium (DMEM), lipopolysaccharide (LPS) (Escherichia coli O26:B6), dexamethasone, diclofenac, and salicylic acid were purchased from Sigma. High-purity standards, including rosmarinic acid, $\alpha$-terpineol, 1,8-cineole, apigenin 7-glucoside, salvianolic acid B, ursolic acid, cinnamic acid, quinic acid, linalyl acetate, viridiflorol, apigenin, carnosol, betulinic acid, oleanolic acid, $\alpha$-humulene, $(-)$-camphor, (+)-borneol, protocatechuic acid, luteolin, camphene, luteolin 7-glucoside, isoquercitrin, p-coumaric acid, apigenin 7-O-glucuronide, linalool, $\alpha$-pinene, carnosic acid, eriocitrin, ferulic acid, and quercetin, were also obtained from Sigma. Celecoxib was obtained from abcr GmbH. CellTiter $96^{\circledR}$ AQueous One Solution Cell Proliferation Assay was obtained from Promega, while dimethyl sulfoxide (DMSO) was purchased from VWR. Formic acid was obtained from PanReac AppliChem. Fetal bovine serum (FBS) and antibiotic/antimycotic solution, TrypLE Express, Roswell Park Memorial Institute (RPMI) 1640 medium, Quant-iT PicoGreen dsDNA Kit, and Micro BCA protein assay kit were obtained from Thermo Fisher Scientific. AlamarBlue ${ }^{\circledR}$ was acquired from Bio-Rad. Human IL- 6 and TNF- $\alpha$ DuoSet enzyme-linked immunosorbent assay (ELISA) and DuoSet ELISA Ancillary Reagent Kit 2 were purchased from R\&D Systems.

\subsection{Bioactive Compounds Extraction}

S. officinalis was purchased from Cantinho das Aromáticas (Porto, Portugal) and grown in an organic environment. After one year of cultivation, the leaves, collected in May before the blooming of the flowers, were dried in the dark at room temperature (RT). The dried leaves were then cut into small pieces and stored in the same conditions until the preparation of the extracts.

To mimic the extracts traditionally prepared by infusion (AE-T) and maceration (HE-T), $200 \mathrm{~mL}$ of boiling water or $100 \mathrm{~mL}$ of hydroethanolic solution (50:50) was added to $10 \mathrm{~g}$ of $S$. officinalis leaves for $10 \mathrm{~min}$ or 5 days, macerating 1 time per day, at RT, respectively. A soxhlet apparatus was also used to prepare AE-S, HE-S, and EE-S from $10 \mathrm{~g}$ of S. officinalis leaves. After each extraction, the solvent was replaced with a new solvent to prevent $S$. officinalis extracts from being exposed to high temperatures, which could result in the thermal decomposition of thermolabile compounds [39]. All extracts were filtrated through a $0.45 \mu \mathrm{m}$ filter and frozen at $-80^{\circ} \mathrm{C}$ and lyophilized (LyoAlfa 10/15, Telstar Technologies, S-L, Terrassa, Spain. Before the freeze-drying of HE, ethanol was evaporated at RT under reduced pressure using a rotary evaporator (IKA VACSTAR D S099, IKA ${ }^{\circledR}$ - Werke GmbH \& Co.KG, Staufen im Breisgau, Germany). This last procedure was used to obtain dried EE-S. After that, the yield extraction in percentage $(\%)$ was calculated by dividing the dry weight of the extracts by the initial weight of leaves. The extracts were stored at $-20{ }^{\circ} \mathrm{C}$ until further use. Three different batches of each extract were prepared. 


\subsection{Determination of the TPC}

TPC of the S. officinalis extracts was measured using the Folin-Ciocalteu method, according to the procedure described by Kontogianni et al. with some modifications [40]. All the extracts $(1 \mathrm{mg} / \mathrm{mL})$ were dissolved in their solvent of extraction (water, ethanol, or their 50:50 mixture). Then, $200 \mu \mathrm{L}$ of the extract was mixed with $4.8 \mathrm{~mL}$ of distilled water and $500 \mu \mathrm{L}$ of Folin-Ciocalteu reagent. After $3 \mathrm{~min}$, $1 \mathrm{~mL}$ saturated solution of $\mathrm{Na}_{2} \mathrm{CO}_{3}(332 \mathrm{~g} / \mathrm{L})$ was added and diluted with distilled water to $10 \mathrm{~mL}$. Blank samples were prepared using $200 \mu \mathrm{L}$ of the respective solvent without $S$. officinalis extracts. After $1 \mathrm{~h}$, a volume of $200 \mu \mathrm{L}$ was pipetted to a 96-well plate, and the absorbance was read at $725 \mathrm{~nm}$ in a microplate reader (Synergy ${ }^{\mathrm{TM}}$ HT Multi-Mode Microplate Reader, BioTek, Winooski, VT, USA). Gallic acid (GA), in concentrations ranging from 25 to $500 \mathrm{mg} / \mathrm{mL}$, was used to prepare the calibration curve to interpolate the content of phenols of each extract. The results are expressed as mg of GA per $g$ of dry S. officinalis extract. All measurements were performed in triplicate for each batch of each extract.

\subsection{Determination of the TFC}

TFC was determined by the aluminum chloride colorimetric method, according to the procedure of Kontogianni et al. with some modifications [40]. One milliliter of $S$. officinalis extracts $(10 \mathrm{mg} / \mathrm{mL})$ dissolved in their solvent of extraction was mixed with $1 \mathrm{~mL}$ of aluminum chloride in ethanol $(20 \mathrm{mg} / \mathrm{mL})$ and diluted with ethanol to $25 \mathrm{~mL}$. Blank samples were prepared with $1 \mathrm{~mL}$ of each extract mixed with 1 drop of acetic acid and diluted to $25 \mathrm{~mL}$. After $40 \mathrm{~min}$ of incubation at RT, $200 \mu \mathrm{L}$ of the resulting solution was pipetted to a 96-well plate, and the absorbance was read at $415 \mathrm{~nm}$ at $20^{\circ} \mathrm{C}$ in a microplate reader (Synergy ${ }^{\mathrm{TM}}$ HT Multi-Mode Microplate Reader, BioTek, Winooski, VT, USA). Rutin (R), in concentrations ranging from 25 to $500 \mathrm{mg} / \mathrm{mL}$, was used to prepare the calibration curve to interpolate the content of flavonoids. The results are expressed as $\mathrm{mg}$ of $\mathrm{R}$ per $\mathrm{g}$ of dry S. officinalis extract. All measurements were performed in triplicate for each batch of each extract.

\subsection{Chromatographic Analyses}

Thin-layer chromatography (TLC) was conducted, in triplicate, according to the procedure described by Exarchou et al. [41]. After application of the samples and standards dissolved in methanol in the plates, they were developed with a mobile phase consisting of chloroform, ethyl acetate, and formic acid $(5: 4: 1, v / v / v)$ in an ascending one-dimensional mode in a saturated glass chamber. After separation and drying the plates, the separated compounds were revealed using iodine and UV light $(254 \mathrm{~nm})$. The retention factor $\left(\mathrm{R}_{\mathrm{F}}\right)$ of each compound in the samples was calculated and compared with the $R_{F}$ of the standards. Afterwards, samples and standards were mixed at the same point of application to demonstrate the presence of that phytochemical compound, since small differences in the $R_{F}$ values are detected by this test.

\subsection{Preparation of S. officinalis Extracts Solutions and IC ${ }_{50}$ Calculation for Antioxidant Activity Assays}

Stock solutions of $S$. officinalis extracts were prepared at concentrations of $500 \mathrm{ug} / \mathrm{mL}$ in the respective buffer of each assay. AE, HE, and EE were dissolved in $25 \%$ of their solvent of extraction. S. officinalis extracts stock solutions were then serially diluted to obtain final concentrations of 5, 10, 25, 75,125 , and $250 \mu \mathrm{g} / \mathrm{mL}$. For all assays, control samples without the extracts but with an equal volume of buffer were also prepared. A control with $25 \%$ of the extraction solvent was also performed to demonstrate its noninterference in the antioxidant activity assessment. The assays were performed in triplicate for each batch of each extract. A microplate reader (Synergy ${ }^{\mathrm{TM}}$ HT Multi-Mode Microplate Reader, BioTek, Vermont, USA) was used to read either the absorbance or the fluorescence. In all antioxidant assays, the extract concentration required to inhibit $50 \%$ of the radical (half-maximal inhibitory concentration $\left.\left(\mathrm{IC}_{50}\right)\right)$, in $\mu \mathrm{g} / \mathrm{mL}$, was calculated by linear or nonlinear regression of the plots presenting the extract concentration $(\mu \mathrm{g} / \mathrm{mL}$, in abscissa) vs. the average $(\%$, in ordinate) of the 
respective radical in the solution. Lower $\mathrm{IC}_{50}$ values mean the higher ability of $S$. officinalis extracts to neutralize the studied radicals.

\subsection{1. $\mathrm{DPPH}^{\bullet}$ Radical Scavenging Activity}

The ability of the S. officinalis extracts to neutralize $\mathrm{DPPH}^{\bullet}$ was determined according to the method described by Cidade et al. [42]. The concentration of $1.9 \mathrm{mM} \mathrm{DPPH}^{\bullet}$ ethanolic solution was adjusted with ethanol in a microplate reader to obtain an absorbance of $0.38 \pm 0.01$ at $515 \mathrm{~nm}\left(25^{\circ} \mathrm{C}\right)$ for $180 \mu \mathrm{L}$ of the radical solution. Then, $20 \mu \mathrm{L}$ of each $S$. officinalis extract at different concentrations in ethanol (Section 2.6) were added to a 96-well plate, and $180 \mu \mathrm{L}$ of $\mathrm{DPPH}^{\bullet}$ ethanolic solution was mixed. The absorbance was immediately recorded at $515 \mathrm{~nm}$ every minute for $60 \mathrm{~min}$ at $25^{\circ} \mathrm{C}$. The neutralization of this radical is accompanied by discoloration of the solution, from deep purple to yellow [43]. Equation (1) was used to calculate the percentage of the $\mathrm{DPPH}^{\bullet}$ in the solution over time:

$$
\mathrm{DPPH}^{\bullet}(\%)=\frac{a b s_{t}=x}{a b s_{t}=0} \times 100
$$

where $a b s_{t=x}$ and $a b s_{t=0}$ is the absorbance of the mixture at a given time and initial absorbance, respectively.

\subsection{2. $\mathrm{ABTS}^{\bullet+}$ Radical Scavenging Activity}

The ability of the $S$. officinalis extracts to scavenge ABTS ${ }^{\bullet+}$ was determined according to the method described by Re et al. with slight modifications [44]. The monocation radical ABTS ${ }^{\bullet+}$ was generated by the reaction between ABTS $(7 \mathrm{mM})$ with the oxidizing agent potassium persulfate $(2.45 \mathrm{mM})$ in an aqueous solution, for $12-16 \mathrm{~h}$, at RT protected from the light. The $\mathrm{ABTS}^{\bullet+}$ radical concentration was adjusted with ethanol to an absorbance of $0.45 \pm 0.01$ at $734 \mathrm{~nm}$ for each $180 \mu \mathrm{L}$ of a radical solution, in a microplate reader, at $30^{\circ} \mathrm{C}$. Then, $20 \mu \mathrm{L}$ of each $S$. officinalis extracts at different concentrations in ethanol (Section 2.6) were added to a 96-well plate, and $180 \mu \mathrm{L}$ of $\mathrm{ABTS}^{\bullet+}$ ethanolic solution was mixed. The decrease in the absorbance was immediately recorded at $734 \mathrm{~nm}$ every minute for $30 \mathrm{~min}$, at $30^{\circ} \mathrm{C}$. $\mathrm{ABTS}^{\bullet+}$ neutralization is accompanied by discoloration of solution from blue to green. The percentage of the $\mathrm{ABTS}^{\bullet+}$ in the solution over time was calculated using Equation (1).

\subsubsection{Antioxidant Activity against $\mathrm{ROO}^{\bullet}$}

The antioxidant activity of $S$. officinalis extracts against ROO ${ }^{\bullet}$ was evaluated according to a method reported in the literature with some modifications [45]. S. officinalis extracts were prepared as described in Section 2.6, but, in this assay, the final concentrations were $0.5,1,2,3,4,5$, and $10 \mu \mathrm{g} / \mathrm{mL}$. Then, $150 \mu \mathrm{L}$ S. officinalis extracts at different concentrations in $75 \mathrm{mM}$ potassium phosphate buffer ( $\mathrm{pH}$ 7.4) were incubated with $25 \mu \mathrm{L}$ of the fluorescent probe fluorescein (final concentration $48 \mathrm{nM}$ ). ROO• were generated by the thermodecomposition of the water-soluble initiator AAPH $(25 \mu \mathrm{L}$, final concentration of $15 \mathrm{mM}$ ) [46]. The fluorescence was immediately recorded with an excitation wavelength of $485 \mathrm{~nm}$ and an emission wavelength of $528 \mathrm{~nm}$, at $37^{\circ} \mathrm{C}$, every minute for $3 \mathrm{~h}$ in a microplate reader. A decrease in fluorescence intensity means that the fluorescein was oxidized by ROO ${ }^{\bullet}$ [46]. Data obtained were converted to relative fluorescence values by dividing the fluorescence intensity at a given time by the fluorescent intensity at $0 \mathrm{~min}$. The antioxidant capacity was calculated for each $\mathrm{S}$. officinalis extract concentration by the area under the curve (AUC), using Equation (2):

$$
\text { Antioxidant Capacity }=\frac{A U C_{\text {extracts }}-A U C_{\text {blk }}}{A U C_{\text {blk }}} \times 100
$$

where $A U C_{\text {extract }}$ corresponds to the AUC obtained for a given concentration of $S$. officinalis extracts, whereas $A U C_{b l k}$ is related to the AUC in the absence of extracts (blank, $0 \mu \mathrm{g} / \mathrm{mL}$ ). The AUC was 
calculated by integrating the relative fluorescence curve as a function of the time using GraphPad Prism 6 software.

\subsubsection{Antioxidant Activity against ${ }^{\circ} \mathrm{NO}$}

The antioxidant activity of different $S$. officinalis extracts against ${ }^{\bullet} \mathrm{NO}$ was measured using Griess reagent, according to the method of Pardau et al. [47]. In a 96-well plate, $20 \mu \mathrm{L}$ of each S. officinalis extracts at different concentrations (Section 2.6) and $80 \mu \mathrm{L}$ SNP $(10 \mathrm{mM})$ in PBS were mixed. The plate was incubated for $15 \mathrm{~min}$ in a water bath at $37{ }^{\circ} \mathrm{C}$ under a tungsten light [48]. In these conditions (physiological $\mathrm{pH}$ and presence of light), SNP reacts spontaneously with oxygen, generating ${ }^{\bullet} \mathrm{NO}$ [49]. - $\mathrm{NO}$ also immediately interacts with oxygen to form nitrogen dioxide $\left(\mathrm{NO}_{2}\right)$, which, in turn, reacts with ${ }^{\bullet} \mathrm{NO}$, generating dinitrogen trioxide $\left(\mathrm{N}_{2} \mathrm{O}_{3}\right)$ [50]. In the presence of water, $\mathrm{N}_{2} \mathrm{O}_{3}$ can generate nitrite ions $\left(\mathrm{NO}_{2}{ }^{-}\right)$, which can be quantified using the Griess reagent. The addition of $1 \% \mathrm{SA}$ in $20 \%$ acetic acid $(50 \mu \mathrm{L})$ led to its diazotization in the presence of $\mathrm{NO}_{2}{ }^{-}$. After $10 \mathrm{~min}, 0.1 \% \mathrm{NED}$ in $2.5 \%$ phosphoric acid $(50 \mu \mathrm{L})$ was added to produce a stable water-soluble pink azo dye, whose absorbance was measured at $540 \mathrm{~nm}$. A $\bullet$ NO scavenger competes with oxygen, donating protons to $\mathrm{NO}_{2}{ }^{-}$, reducing its production, and, therefore, the absorbance, which can be used as an indirect indicator of ${ }^{\bullet} \mathrm{NO}$ concentration. The percentage of nitrite in the solution was determined according to the followed Equation (3):

$$
\mathrm{NO}_{2}^{-} \text {or } \mathrm{O}_{2}^{\bullet-}(\%)=\frac{\mathrm{abs}_{\text {extract }}}{\mathrm{abs}_{\text {control }}} \times 100
$$

where $\mathrm{abs}_{\text {control }}$ is the absorbance of the control $(0 \mu \mathrm{g} / \mathrm{mL})$ and absextract is the absorbance in the presence of $S$. officinalis extracts at different concentrations.

\subsubsection{Antioxidant Activity against $\mathrm{O}_{2}^{\bullet-}$}

A method from Fernandes et al. was used to determine the antioxidant activity against $\mathrm{O}_{2}{ }^{\bullet-}$ [48]. In the presence of oxygen, $\mathrm{O}_{2}{ }^{\bullet-}$ were generated by the NADH/PMS system, which will reduce the NBT to a blue chromogen [48]. This could be prevented in the presence of an antioxidant. In a 96-well plate, $26.1 \mu \mathrm{L}$ of $S$. officinalis extracts at different concentrations in PBS (Section 2.6), $75 \mu \mathrm{L}$ of NADH (final concentration $166 \mu \mathrm{M}$ ), $150 \mu \mathrm{L}$ of NBT (final concentration $43 \mu \mathrm{M}$ ), and $10 \mu \mathrm{L}$ of PMS (final concentration of $2.7 \mu \mathrm{M}$ ) were mixed. The absorbance was immediately recorded at $560 \mathrm{~nm}$ for $2 \mathrm{~min}$ at RT. The percentage of $\mathrm{O}_{2}{ }^{\bullet-}$ in the solution was determined according to Equation (3).

\subsubsection{RP Capacity}

The capacity of the S. officinalis extracts to convert $\mathrm{Fe}^{3+}$ into $\mathrm{Fe}^{2+}$ (reducing power (RP)) was investigated according to a method described by Martins et al. with some modifications [43]. To each S. officinalis extract at different concentrations $(500 \mu \mathrm{L})$ in $200 \mathrm{mM}$ sodium phosphate buffer, $\mathrm{pH}$ 6.6, (Section 2.6) were added $500 \mu \mathrm{L}$ sodium phosphate buffer and $500 \mu \mathrm{L}$ ferricyanide $(1 \% w / v)$. The mixture solution was incubated at $50{ }^{\circ} \mathrm{C}$ for $20 \mathrm{~min}$. Then, $500 \mu \mathrm{L}$ trichloroacetic acid $(10 \% w / v)$ was added. Antioxidant species reduce the ferrocyanide reagent $\left[\mathrm{K}_{4} \mathrm{Fe}(\mathrm{CN})_{6}\right]$, forming $\mathrm{K}_{3} \mathrm{Fe}(\mathrm{CN})_{6}$. From this solution, $114 \mu \mathrm{L}$ were removed and added to a 96-well plate, together with $114 \mu \mathrm{L}$ of deionized water and $23 \mu \mathrm{L}$ of ferric chloride $(0.1 \% w / v)$. The mixtures were homogenized and left at RT for $4 \mathrm{~h}$. The ferrous amount could then be determined by the formation of Peal's Prussian blue: the addition of ferric chloride $\left(\mathrm{FeCl}_{3}\right)$ allowed the generation of a blue-colored product $\left(\mathrm{KFe}\left[\mathrm{Fe}(\mathrm{CN})_{6}\right]\right)$ that could be determined spectrophotometrically at $690 \mathrm{~nm}$. An increase in the absorbance indicates an increase in the reduction of $\mathrm{Fe}^{3+}$ into $\mathrm{Fe}^{2+}$ by S. officinalis extracts. In this assay, the $\mathrm{IC}_{50}$ is the extract concentration that provides a 0.5 absorbance. Higher $\mathrm{IC}_{50}$ values correspond to the higher ability of $S$. officinalis extracts to convert $\mathrm{Fe}^{3+}$ into $\mathrm{Fe}^{2+}$. 


\subsection{Preparation of S. officinalis Extracts Solution for Biological Studies}

For cytotoxic assays, HE and EE were firstly dissolved in $0.4 \%$ and $1 \%$ DMSO, respectively. DMEM was then added to obtain a stock solution of $250 \mu \mathrm{g} / \mathrm{mL}$. For immunomodulatory assays, aliquots of the stock solutions (12.8 mg/mL for AE and $60.0 \mathrm{mg} / \mathrm{mL}$ for HE and EE) of each S. officinalis extract were also prepared and stored at $-80^{\circ} \mathrm{C}$. AE were completed dissolved in complete RPMI medium, while $\mathrm{EE}$ and DE were dissolved in DMSO. The percentage of DMSO in the well was $0.33 \%$ for the maximal concentration tested of HE and EE. Then, both stock solutions were sterilized with a $0.22 \mu \mathrm{m}$ filter and diluted to final concentrations of $5,10,25,75,125$, and $250 \mu \mathrm{g} / \mathrm{mL}$ in the respective medium. A DMSO screening was performed before, and the metabolic activity was not affected by the percentages used.

\subsection{Cytotoxicity Evaluation}

\subsubsection{Cell Culture and Seeding}

The cytotoxic effect of $S$. officinalis extracts in the presence of the mouse adipose fibroblast cell line (L929) was evaluated according to a procedure described by Vieira et al. with some modifications [51]. The L929 cell line was cultured in low-glucose DMEM supplemented with $10 \%$ FBS and $1 \%$ antibiotic/antimycotic solution at $37{ }^{\circ} \mathrm{C}$ in an atmosphere of $5 \% \mathrm{CO}_{2}$. Before performing the seeding, the confluent cells, at passages 19-22, were detached from the culture flask by using TrypLE Express. The L929 cell line was seeded at a density of $1 \times 10^{4}$ cells/well in an adherent 24-well culture plate and incubated for $24 \mathrm{~h}$ at $37^{\circ} \mathrm{C}$ in a humidified atmosphere with $5 \% \mathrm{CO}_{2}$. The culture medium was removed, and the same volume $(1 \mathrm{~mL})$ of different $S$. officinalis extracts at different concentrations (Section 2.7) was added. The L929 cell line in culture was incubated with the extracts for 24, 48, and $72 \mathrm{~h}$, and the metabolic activity, DNA quantification, total protein content, and morphology of cells were evaluated for each time point. The negative control comprised the culture of the L929 cell line in medium $(0 \mu \mathrm{g} / \mathrm{mL})$ for each respective extract.

\subsubsection{Metabolic Activity}

The metabolic activity of the L929 cell line was determined by the dehydrogenase activity of cells using the MTS assay, according to manufacturer's instructions. After 24, 48, and $72 \mathrm{~h}$ of culture, the culture medium was removed, and the L929 cell line was gently washed twice with sterilized PBS. Serum-free culture medium without phenol red and MTS reagent were added to each well at a ratio of 5:1. MTS reagent was used as blank. Cells were incubated at $37^{\circ} \mathrm{C}$ for $3 \mathrm{~h}$ in a humidified atmosphere containing $5 \% \mathrm{CO}_{2}$. Thereafter, the absorbance of the MTS reaction medium from each sample was recorded in triplicate at $490 \mathrm{~nm}$ in a microplate reader. The results are expressed in percentage with respect to the control.

\subsubsection{DNA Quantification}

Cell proliferation was determined using a fluorimetric dsDNA quantification kit, performed according to the manufacturer's instructions. After 24,48 , and $72 \mathrm{~h}$ of culture, the culture medium was removed, and the L929 cell line was gently washed with sterilized PBS. Then, $1 \mathrm{~mL}$ of ultrapure water was added to each well. After $30 \mathrm{~min}$, the samples were collected, transferred into Eppendorf tubes, and frozen at $-80^{\circ} \mathrm{C}$. The thawed samples were sonicated $(15 \mathrm{~min})$, and $28.7 \mu \mathrm{L}$ of the sample or standard ( 0 to $2 \mu \mathrm{g} / \mathrm{mL}$ ) was added in triplicate to the white opaque 96-well plate, followed by PicoGreen solution $(71.3 \mu \mathrm{L})$ and Tris-EDTA (TE) buffer $(100 \mu \mathrm{L})$. The plate was incubated for $10 \mathrm{~min}$ in the dark, and the fluorescence of each sample was measured in a microplate reader (EX $=485 \mathrm{~nm}$ and $\mathrm{EM}=528 \mathrm{~nm})$. The DNA concentration $(\mu \mathrm{g} / \mathrm{mL})$ of each sample was calculated using the standard curve relating to the DNA concentration and the fluorescence intensity. The results are expressed in relative DNA concentration of the control. 


\subsubsection{Total Protein Content}

A micro bicinchoninic acid (BCA) protein assay kit was used for the quantification of total protein content, according to the manufacturer's instructions. Samples were collected and prepared for assaying as described in DNA quantification. Then, $150 \mu \mathrm{L}$ of samples and bovine serum albumin (BSA) standards ( 0 to $40 \mu \mathrm{g} / \mathrm{mL})$, in triplicate, were mixed with the working reagent $(150 \mu \mathrm{L})$ in a 96-well plate and incubated at $37^{\circ} \mathrm{C}$ for $2 \mathrm{~h}$ in the dark. After that, the absorbance was read at $562 \mathrm{~nm}$ using a microplate reader. The total protein content $(\mu \mathrm{g} / \mathrm{mL})$ of each sample was calculated using the standard curve relating to the BSA concentration and the absorbance intensity. The results are expressed in relative total protein content of the control.

\subsubsection{Cell Morphology}

A high-resolution field emission scanning electron microscope (HR-SEM, Auriga Compact, ZEISS) was used to analyze the morphology of the L929 cell line. After 24,48 , and $72 \mathrm{~h}$ of culture, the medium was removed, and the L929 cell line was rinsed with sterile PBS. To fix the cells to the bottom of the plate, $2.5 \%$ glutaraldehyde in PBS solution was added, and the plates were kept at $4{ }^{\circ} \mathrm{C}$. The samples were dehydrated with increasing concentrations of ethanol $(10 \%, 20 \%, 30 \%, 40 \%, 50 \%, 60 \%, 70 \%$, $80 \%, 90 \%$, and $100 \%$ ) and dried overnight at RT. Afterwards, the bottom of the well was melted with a soldering-iron and placed in the stub. The samples were then sputter-coated (EM ACE600, Leica Mikrosysteme $\mathrm{GmbH}$, Wien, Austria) with gold-palladium, and the micrographs were recorded at $5 \mathrm{kV}$ with magnifications of $200 \times$ and $1000 \times$.

\subsection{Proinflammatory Activity Evaluation}

Proinflammatory activity of $S$. officinalis extracts was evaluated using a human peripheral blood monocyte cell line (THP-1), obtained from American Type Culture Collection (ATCC ${ }^{\circledR}$ TIB-202 ${ }^{\mathrm{TM}}$ ), according to a modified procedure described elsewhere [52,53]. The THP- 1 cell line, at passages 9-14, was cultured in RPMI medium supplemented with 10\% FBS and 1\% antibiotic/antimycotic solution at $37^{\circ} \mathrm{C}$ in an atmosphere of $5 \% \mathrm{CO}_{2}$. The cells were seeded at a density of $5 \times 10^{5}$ cells in an adherent 24-well culture plate. For the induction of THP-1 cell differentiation, the RPMI medium containing $100 \mathrm{nM}$ phorbol 12-myristate 13-acetate (PMA) was added and incubated for $24 \mathrm{~h}$. After this period of time, the nonattached cells were removed by aspiration, and the adherent cells were washed twice with warm RPMI medium. To ensure the reversion of monocyte to a resting macrophage phenotype, the cells were incubated for an additional $48 \mathrm{~h}$ in RPMI without PMA. Afterwards, the medium was changed, and each S. officinalis extracts at different concentrations (Section 2.7) were added to the nonstimulated macrophages. After a period of incubation of $24 \mathrm{~h}$, the culture medium was harvested (the triplicates were mixed and homogenized) and stored aliquoted at $-80^{\circ} \mathrm{C}$ until cytokine quantification. The cells were washed with warm sterile PBS, and the metabolic activity and DNA quantification were performed. The cell morphology was analyzed before collecting the medium under an inverted microscope (Axio Vert.A1, Carl Zeiss Microscopy GmbH, Göttingen, Germany).

\section{Metabolic Activity}

The metabolic activity of nonstimulated macrophages incubated with S. officinalis extracts was determined by the reduction of the resazurin (blue) to resorufin (pink) by living macrophages using the alamarBlue assay. RPMI medium containing $10 \%$ alamarBlue was added to each well. A blank was also made ( $10 \%$ alamarBlue without cells). The cells were incubated at $37^{\circ} \mathrm{C}$ for $4 \mathrm{~h}$ in a humidified atmosphere containing $5 \% \mathrm{CO}_{2}$. Thereafter, the absorbance of the alamarBlue reduction from each sample was recorded in triplicate at 600 and $570 \mathrm{~nm}$ on a microplate reader. The results are expressed in percentage related to the control. 


\subsection{Anti-Inflammatory Activity Evaluation}

The THP-1 cell line was seeded and cultured, as previously described (Section 2.9). After the total reversion of monocyte to macrophage phenotype, macrophages were stimulated with $100 \mathrm{ng} / \mathrm{mL}$ of LPS in fresh medium for $2 \mathrm{~h}$ to provide an inflammatory stimulus. S. officinalis extracts at different concentrations (Section 2.7) were then added to the LPS-stimulated macrophages and incubated for $22 \mathrm{~h}$. Afterwards, the culture medium was harvested and stored as previously described. The cells were then washed with warm sterile PBS, and the metabolic activity, DNA quantification, and morphology were assessed, as previously described. LPS-stimulated macrophages cultured without extracts (only with culture medium, $0 \mu \mathrm{g} / \mathrm{mL}$ ) were used as a positive control to stimulate IL-6 production. Dexamethasone, diclofenac, salicylic acid, and celecoxib at $10 \mu \mathrm{M}$, dissolved in ethanol, were used as positive controls of cytokine production inhibition. The negative control was cells without LPS stimulation.

\section{IL-6 and TNF- $\alpha$ Quantification}

The amount of IL- 6 and TNF- $\alpha$ was assayed using an ELISA kit, according to the manufacturer's instructions. The obtained values were normalized by the respective DNA concentration. The results are expressed in percentage related to the positive control.

\subsection{Statistical Analysis}

The results were obtained as 3 independent experiments with a minimum of 3 replicates for each condition and are expressed as mean \pm standard deviation (SD). Statistical analyses were performed using GraphPad Prism 6.0 software. Analysis of variance (ANOVA) and Tukey's multiple comparisons test were used for yield extraction, total phenolic and flavonoid content, and antioxidant activity. Analysis of variance (ANOVA) and Dunnett's multiple comparison method were used for cell assays. Differences between experimental groups were considered significant with a confidence interval of $99 \%$, whenever $p<0.01$.

\section{Results}

\subsection{Extraction Yield}

The extraction yield obtained for each extraction method is illustrated in Figure 1A. In the soxhlet extraction, similar extraction yields were obtained using a hydroethanolic solution (50:50) or water, $30.6 \pm 2.7 \%$ and $29.9 \pm 0.2 \%$, respectively. The extraction with ethanol led to a significantly lower extraction yield $(12.2 \pm 0.3 \%)$ in comparison with the previous solvents. In the traditional extraction, the extraction yield was significantly higher using the hydroethanolic solution $(24.2 \pm 5.3 \%)$, followed by water $(15.3 \pm 0.3 \%)$. Comparing both techniques, significant differences were observed only for AE, where AE-S promoted a higher extraction yield than AE-T. Analyzing all the S. officinalis extracts, HE-S had a similar yield to AE-S, followed by HE-T, AE-T, and EE-S. 

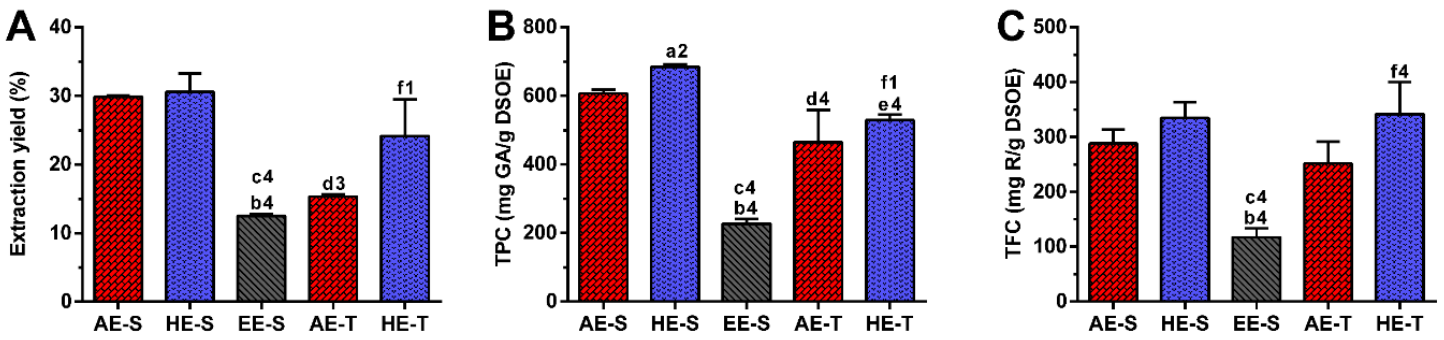

Figure 1. Extracts yield (A), total phenolic (TPC) (B), and flavonoid (TFC) (C) contents of Salvia officinalis extracts. Statistically significant differences are 1 ( $p<0.0257), 2(p<0.0037), 3(p<0.0004)$, and 4 $(p<0.0001)$ in comparison with a (AE-S vs. HE-S), b (AE-S vs. EE-S), c (HE-S vs. EE-S), d (AE-S vs. AE-T), e (HE-S vs. HE-T), and f (AE-T vs. HE-T). GA: gallic acid; R: rutin; DSOE: dry Salvia officinalis extract; AE: aqueous extracts; HE: hydroethanolic extracts; EE: ethanolic extracts; S: soxhlet extraction; $\mathrm{T}$ : traditional extraction.

\subsection{TPC and TFC}

The TPC and TPF of S. officinalis extracts are presented in Figure 1B,C, respectively. The TPC was significantly higher in HE-S (685.2 $\pm 6.6 \mathrm{mg} \mathrm{GA} / \mathrm{g}$ DSOE), followed by AE-S $(606.3 \pm 11.5 \mathrm{mg} \mathrm{GA} / \mathrm{g}$ DSOE) and EE-S (227.2 $\pm 13.2 \mathrm{mg}$ GA/g DSOE). In traditional extraction, HE-T significantly recovered a higher phenol content (528.8 $\pm 17.1 \mathrm{mg}$ GA/g DSOE) compared with AE-T (464.5 $\pm 94.0 \mathrm{mg}$ GA/g DSOE). Moreover, a significantly higher TPC was observed in AE-S and HE-S compared with AE-T and HE-T. Analyzing all the S. officinalis extracts, HE-S presented a higher amount of TPC, followed by AE-S, HE-T, AE-T, and EE-S.

Similar amounts of flavonoids were found in soxhlet extraction performed with HE-S (334.7 $\pm 29.3 \mathrm{mg}$ R/g DSOE) and AE-S $(287.9 \pm 25.2 \mathrm{mg}$ R/g DSOE), while EE-S extracted significantly lower TFC (117.0 $\pm 16.7 \mathrm{mg}$ R/g DSOE). HE-T recovered a significantly higher flavonoid content (342.0 $\pm 57.7 \mathrm{mg}$ R/g DSOE) compared with AE-T (251.6 $\pm 40.1 \mathrm{mg}$ R/g DSOE). No statistically significant differences in TFC were found for both extraction techniques, being the values similar. Analyzing all the S. officinalis extracts, HE-S and HE-T presented a higher amount of TFC, followed by AE-S, AE-T, and EE-S.

\subsection{TLC Analysis of S. officinalis Extracts}

TCL analysis of the five S. officinalis extracts revealed similar chromatographic profiles (Figure 2). Several standards were tested; however, at most, only three different spots appeared in the S. officinalis extracts. Rosmarinic acid $\left(R_{F}=0.443 \pm 0.007\right)$ appeared in all extracts. Carnosol $\left(R_{F}=0.935 \pm 0.012\right)$ and carnosic acid $\left(R_{F}=0.948 \pm 0.017\right)$, with a specific shape, could be observed in HE-S and EE-S. The samples and standards together corroborated these observations. 


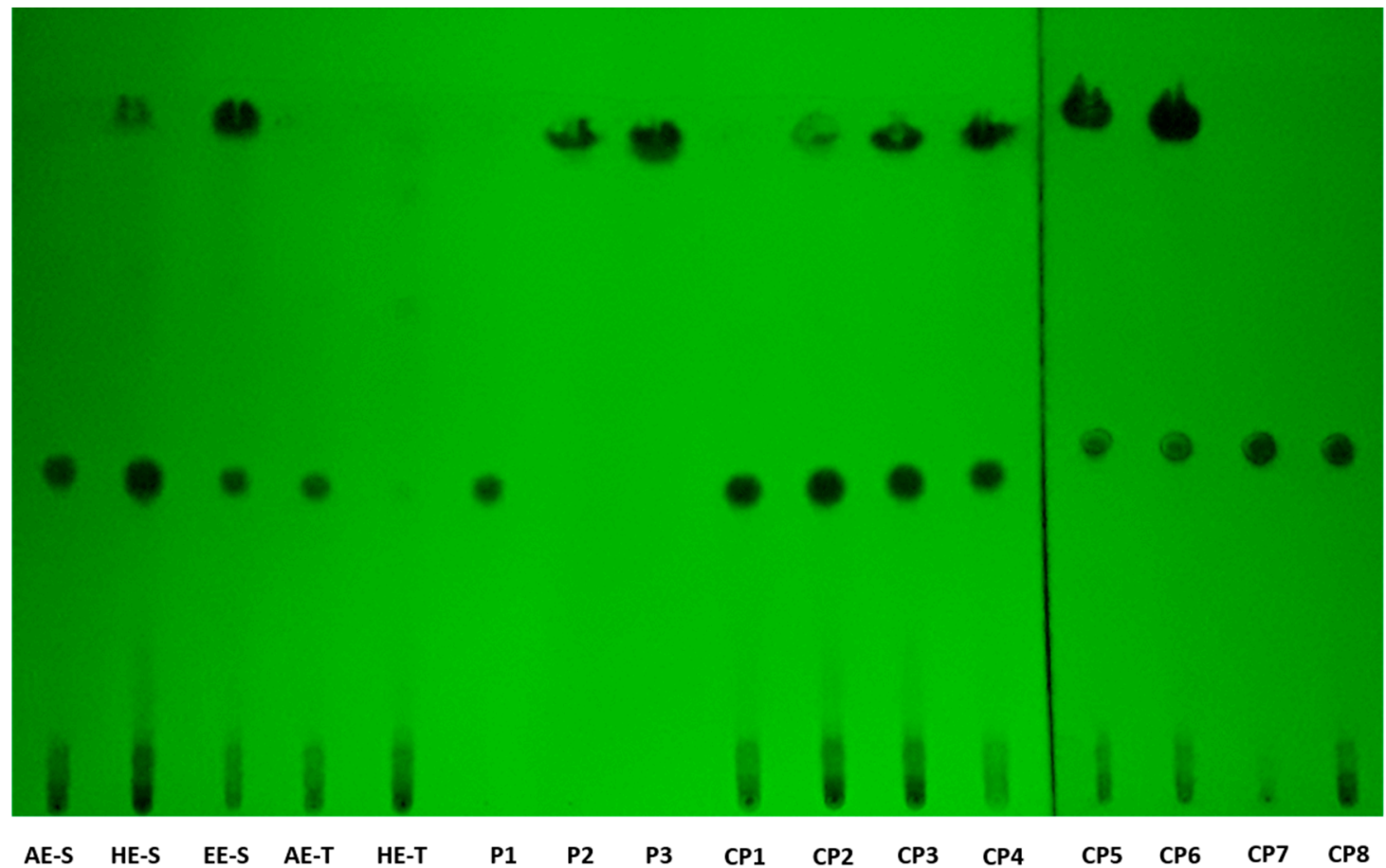

Figure 2. Thin-layer chromatography (TLC) chromatogram of Salvia officinalis extracts and standards. AE: aqueous extracts; HE: hydroethanolic extracts; EE: ethanolic extracts; S: soxhlet extraction; T: traditional extraction; P1: rosmarinic acid, P2: carnosol; P3: carnosic acid; CP1: AE-S + P1; CP2: HE-S + P1; CP3: HE-S + P2; CP4: EE-S + P1; CP5: EE-S + P2; CP6: EE-S + P3; CP7: AE-T + P1; CP8: HE-T + P1.

\subsection{Antiradical Activity of S. officinalis Extracts against DPPH and ABTS $\bullet$}

A screening of the antiradical activity of $S$. officinalis extracts was firstly evaluated against the most common radicals, namely $\mathrm{DPPH}^{\bullet}$ and $\mathrm{ABTS}^{\bullet+}$, due to their simple measurement. The $\mathrm{IC}_{50}(\mu \mathrm{g} / \mathrm{mL})$ of each S. officinalis extract is presented in Figure 3. All S. officinalis extracts showed antiradical activity against $\mathrm{DPPH}^{\bullet}$ (Figure S1) and $\mathrm{ABTS}^{\bullet+}$ (Figure S2) in a concentration-dependent manner.
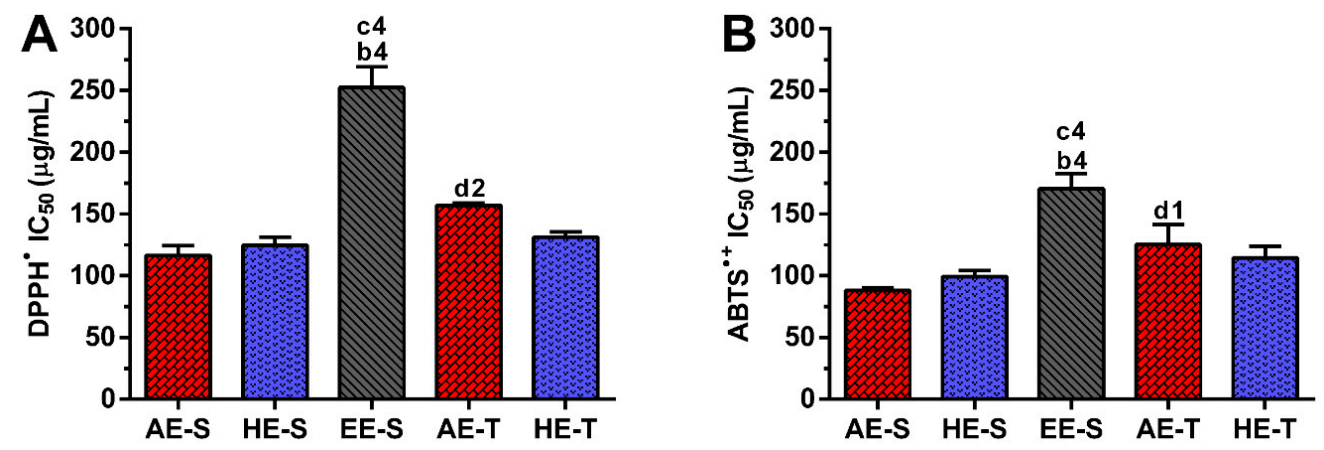

Figure 3. Half-maximal inhibitory concentration $\left(\mathrm{IC}_{50}, \mu \mathrm{g} / \mathrm{mL}\right)$ of the different Salvia officinalis extracts against $\mathrm{DPPH}^{\bullet}(\mathbf{A})$ and $\mathrm{ABTS}^{\bullet+}(\mathbf{B})$. Statistically significant differences are $1(p<0.0128), 3(p<0.0081)$, and $4(p<0.0001)$ in comparison with b (AE-S vs. EE-S), c (HE-S vs. EE-S), and d (AE-S vs. AE-T). AE: aqueous extracts; HE: hydroethanolic extracts; EE: ethanolic extracts; S: soxhlet extraction; T: traditional extraction.

In the soxhlet extraction, the $\mathrm{IC}_{50}$ for $\mathrm{DPPH}^{\bullet}$ of AE-S $(116.5 \pm 7.9 \mu \mathrm{g} / \mathrm{mL})$ and HE-S $(124.7 \pm 6.6 \mu \mathrm{g} / \mathrm{mL})$ did not present significant differences, but both were significantly lower in comparison with EE-S $(252.3 \pm 17.0 \mu \mathrm{g} / \mathrm{mL})$ (Figure 3A). In the traditional extraction, AE-T $(157.0 \pm 1.9 \mu \mathrm{g} / \mathrm{mL})$ and HE-T $(131.3 \pm 4.1 \mu \mathrm{g} / \mathrm{mL})$ also did not show significant differences in the $\mathrm{IC}_{50}$ 
values. Comparing both techniques, significant differences were observed only for AE as AE-S showed higher antiradical activity than AE-T. No differences were found for HE, being the values similar. Analyzing all the $S$. officinalis extracts, AE-S presented higher $\mathrm{DPPH}^{\bullet}$ scavenging activity, followed by HE-S, HE-T, AE-T, and EE-S.

AE-S $(88.2 \pm 2.3 \mu \mathrm{g} / \mathrm{mL})$ and HE-S $(99.3 \pm 4.1 \mu \mathrm{g} / \mathrm{mL})$ showed similar $\mathrm{IC}_{50}$ against ABTS $^{\bullet+}$, but significantly higher activity in comparison with EE-S $(170.6 \pm 12.1 \mu \mathrm{g} / \mathrm{mL}$ ) (Figure 3B). In the traditional extraction, HE-T $(114.5 \pm 9.6 \mu \mathrm{g} / \mathrm{mL})$ had a comparable $\mathrm{IC}_{50}$ to the AE-T $(125.2 \pm 16.1 \mu \mathrm{g} / \mathrm{mL})$. Comparing both extraction techniques, only AE showed significant differences, presenting the soxhlet extraction extracts the lowest $\mathrm{IC}_{50}$. Analyzing all the $S$. officinalis extracts, AE-S presented higher $\mathrm{ABTS}^{\bullet+}$ scavenging activity, followed by HE-S, HE-T, AE-T, and EE-S.

\subsection{Antioxidant Activity against $\mathrm{ROO}^{\bullet}$}

All S. officinalis extracts showed scavenging activity for $\mathrm{ROO}^{\bullet}$ in a concentration-dependent manner (Figure S3). The antioxidant activity against ROO ${ }^{\bullet}$ (Figure $4 \mathrm{~A}$ ) was similar for HE-S $(0.52 \pm 0.02 \mu \mathrm{g} / \mathrm{mL})$ and AE-S $(0.61 \pm 0.02 \mu \mathrm{g} / \mathrm{mL})$ and significantly higher compared to EE-S $(1.35 \pm 0.12 \mu \mathrm{g} / \mathrm{mL})$. The same tendency occurred in the traditional extraction, where $\mathrm{IC}_{50}$ values from AE-T $(0.69 \pm 0.12 \mu \mathrm{g} / \mathrm{mL})$ and HE-T $(0.52 \pm 0.10 \mu \mathrm{g} / \mathrm{mL})$ did not present statistical differences. Extracts obtained with a soxhlet or by the traditional method presented a similar antioxidant activity against ROO' ${ }^{\bullet}$. Analyzing all the S. officinalis extracts, HE-S and HE-T presented higher antioxidant activity against ROO ${ }^{\bullet}$, followed by AE-S, AE-T, and EE-S.
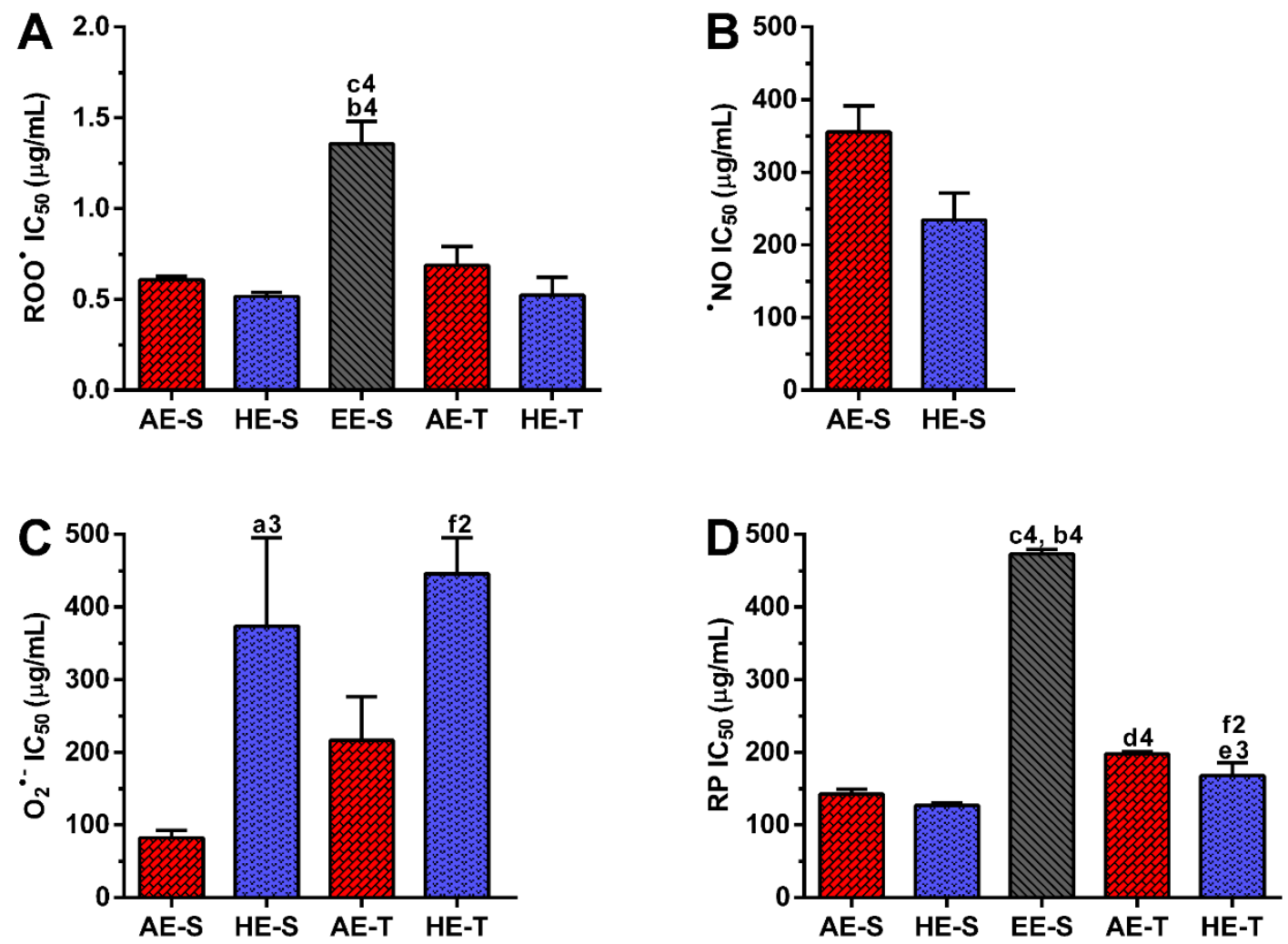

Figure 4. Half-maximal inhibitory concentration $\left(\mathrm{IC}_{50}, \mu \mathrm{g} / \mathrm{mL}\right)$ of the different Salvia officinalis extracts against $\mathrm{ROO}^{\bullet}(\mathbf{A}),^{\bullet} \mathrm{NO}(\mathbf{B})$, and $\mathrm{O}_{2}{ }^{\bullet-}(\mathbf{C})$, as well as their reducing power (RP) (D). Statistically significant differences are 1 ( $p<0.0105), 2(p<0.0032), 3(p<0.0002), 4(p<0.0001)$ in comparison with a (AE-S vs. HE-S), b (AE-S vs. EE-S), c (HE-S vs. EE-S), d (AE-S vs. AE-T), e (HE-S vs. HE-T), and $f$ (AE-T vs. HE-T). AE: aqueous extracts; HE: hydroethanolic extracts; EE: ethanolic extracts; S: soxhlet extraction; T: traditional extraction. 


\subsection{Antioxidant Activity against $\bullet N O$}

The different types of $S$. officinalis extracts presented the ability to scavenge ${ }^{\circ O}$ in a concentration-dependent manner (Figure S4). In this assay, EE-S, AE-T, and HE-T did not present the ability to reduce $50 \%$ of the ${ }^{\bullet} \mathrm{NO}$ amount. HE-S $(234.6 \pm 36.9 \mu \mathrm{g} / \mathrm{mL})$ showed to have more antioxidant effects against ${ }^{\bullet} \mathrm{NO}$ in comparison with AE-S (355.6 $\left.\pm 35.9 \mu \mathrm{g} / \mathrm{mL}\right)$ (Figure 4B). At a concentration of $500 \mu \mathrm{g} / \mathrm{mL}$, HE-S neutralized $56.26 \pm 5.5 \%$ of nitrite, followed by AE-S (50.93 $\pm 2.7 \%)$, EE-S $(43.23 \pm 3.8 \%)$, HE-T $(41.59 \pm 1.0 \%)$, and AE-T $(38.54 \pm 3.0 \%)$.

\subsection{Antioxidant Activity against $\mathrm{O}_{2}^{\bullet-}$}

The different $S$. officinalis extracts showed scavenging activity for $\mathrm{O}_{2}{ }^{\bullet-}$ in a concentration-dependent manner (Figure S5). The $\mathrm{IC}_{50}$ was significantly higher for AE-S $(82.3 \pm 10.0 \mu \mathrm{g} / \mathrm{mL})$ compared to HE-S $(378.4 \pm 128.8 \mu \mathrm{g} / \mathrm{mL}$ ) (Figure $4 \mathrm{C}$ ) but was not possible to calculate for EE-S. The same behavior was observed in the traditional extraction, where the antioxidant activity against $\mathrm{O}_{2}^{\bullet-}$ was significantly higher for AE-T $(216.3 \pm 60.0 \mu \mathrm{g} / \mathrm{mL})$ in comparison with HE-T $(450.7 \pm 56.8 \mu \mathrm{g} / \mathrm{mL})$. There are no significant differences between the different extraction techniques. At a concentration of $500 \mu \mathrm{g} / \mathrm{mL}$, AE-T neutralized $70.3 \pm 5.5 \%$ of $\mathrm{O}_{2}{ }^{\bullet-}$, followed by AE-S $(68.9 \pm 4.1 \%)$, HE-T $(61.5 \pm 5.9 \%)$, HE-S $(53.3 \pm 12.7 \%)$, and EE-S $(25.8 \pm 8.6 \%)$.

\subsection{RP Scavenging Activity}

All S. officinalis extracts showed RP in a concentration-dependent manner (Figure S6). In the soxhlet extraction, no differences were observed in the $\mathrm{IC}_{50}$ values for RP between HE-S $(126.9 \pm 3.9 \mu \mathrm{g} / \mathrm{mL})$ and AE-S $(142.3 \pm 6.7 \mu \mathrm{g} / \mathrm{mL}$ ) (Figure 4D). However, both extracts presented significant differences in comparison with EE-S $(473.0 \pm 6.1 \mu \mathrm{g} / \mathrm{mL})$. Traditional extraction provided HE-T $(167.5 \pm 18.0 \mu \mathrm{g} / \mathrm{mL})$ with lower reducing power in comparison with AE-T (197.4 $\pm 3.4 \mu \mathrm{g} / \mathrm{mL})$. Significant differences were observed in AE and HE obtained from soxhlet extraction or traditional extraction. Analyzing all the S. officinalis extracts, HE-S presented lower RP, followed by AE-S, HE-T, AE-T, and EE-S.

\subsection{Cytotoxicity of S. officinalis Extracts}

\subsubsection{L929 Cell Line}

The cytotoxicity of the different $S$. officinalis extracts was firstly performed with a mouse adipose fibroblasts cell line (L929). Figure 5 shows the metabolic activity, cell proliferation, and total protein content of the fibroblasts in the presence or absence of $S$. officinalis extracts for $72 \mathrm{~h}$ of culture. AE-S did not compromise the metabolic activity of fibroblasts for concentrations lower than $125 \mu \mathrm{g} / \mathrm{mL}$, while HE-S and EE-S affected the metabolic activity for concentrations higher than $75 \mu \mathrm{g} / \mathrm{mL}$ for $72 \mathrm{~h}$ of culture (Figure 5A) in comparison with control $(0 \mu \mathrm{g} / \mathrm{mL})$. Additionally, EE-S significantly affected the metabolic activity of fibroblasts for concentrations higher than $25 \mu \mathrm{g} / \mathrm{mL}$ in the first $24 \mathrm{~h}$ of culture. However, the cells were able to recover their metabolic activity in the next $24 \mathrm{~h}$. Fibroblasts were able to proliferate (Figure 5B) and synthesize protein (Figure 5C) for $72 \mathrm{~h}$ of culture when incubated with the S. officinalis extracts for the above-mentioned concentrations. In the traditional extraction, AE-T in all tested concentrations did not affect the metabolic activity (Figure 5A), even the cell proliferation (Figure 5B) and protein content (Figure 5C), of fibroblasts in all tested concentrations for $72 \mathrm{~h}$ of cell culture. HE-T significantly influenced the metabolic activity (Figure 5A), as well as the cell proliferation (Figure 5B) and protein content (Figure 5C), for concentrations higher than $125 \mu \mathrm{g} / \mathrm{mL}$ for $72 \mathrm{~h}$ of culture. 

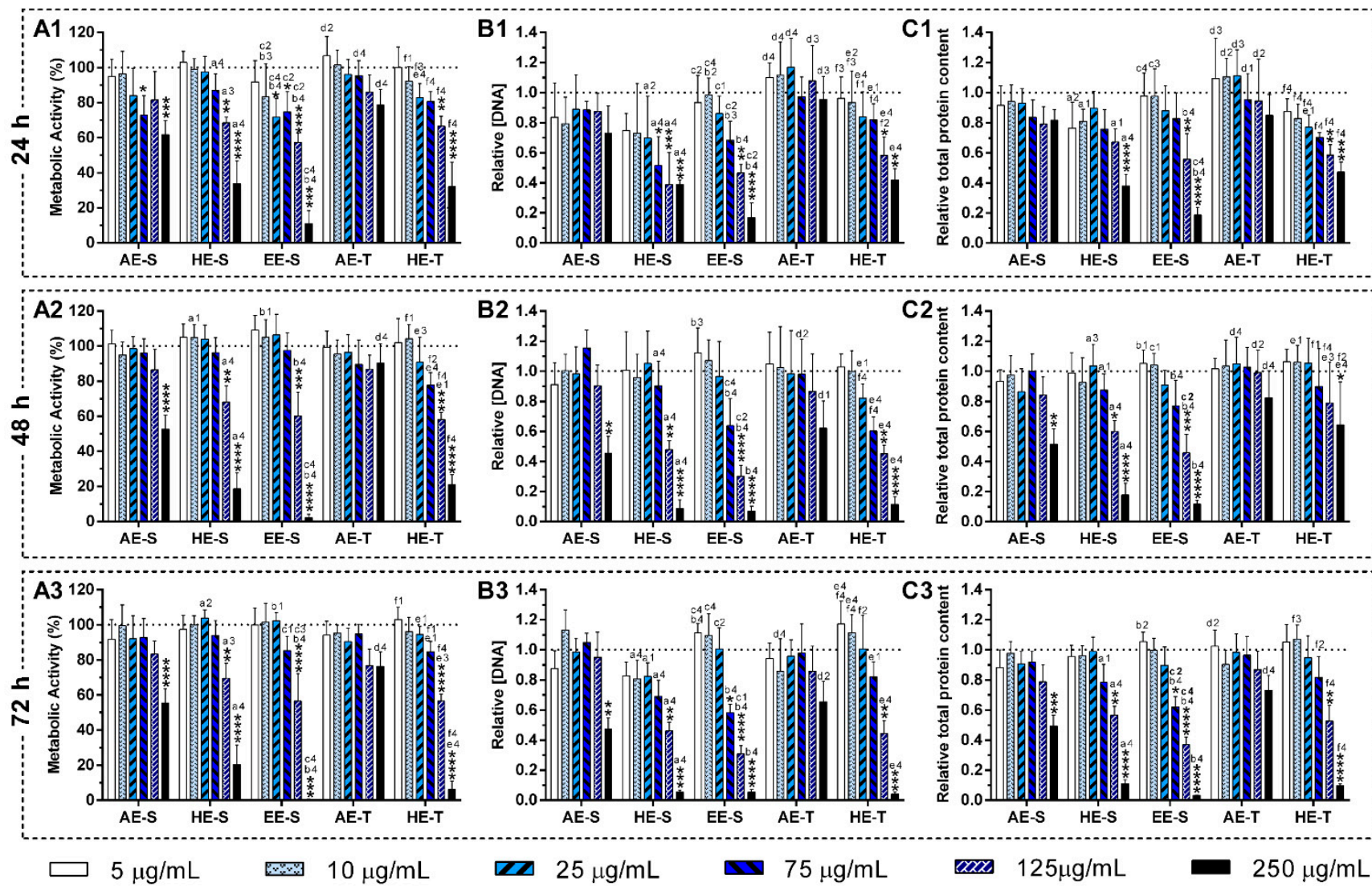

Figure 5. Metabolic activity (A), relative DNA concentration (B) and relative total protein content (C) of the L929 cell line in the presence of different concentrations of the Salvia officinalis extracts over $24 \mathrm{~h}$ (A1, B1, and C1), $48 \mathrm{~h}$ (A2, B2, and C2), and $72 \mathrm{~h}$ (A3, C3 and B3) of culture. The dotted line represents the nontreated condition $(0 \mu \mathrm{g} / \mathrm{mL})$ for each assay. Statistically significant differences are ${ }^{*}(p<0.0466),{ }^{* *}(p<0.0093),{ }^{* * *}(p<0.0010)$, and ${ }^{* * *}(p<0.0001)$ in comparison with the negative control $(0 \mathrm{mg} / \mathrm{mL})$ for each different Salvia officinalis extracts, and $1(p<0.0496), 2(p<0.0085), 3(p<0.0009)$, and 4 ( $p<0.0001)$ in comparison with a (AE-S vs. HE-S), b (AE-S vs. EE-S), c (HE-S vs. EE-S), d (AE-S vs. AE-T), e (HE-S vs. HE-T), and f (AE-T vs. HE-T). AE: aqueous extracts; HE: hydroethanolic extracts; EE: ethanolic extracts; S: soxhlet extraction; T: traditional extraction. 
Cell morphology was not affected at cytocompatible concentrations of S. officinalis extracts during the culture time considered, according to HR-SEM micrographs (Figures S7-S12). All the samples presented a typical elongated morphology and pronounced filopodia similar to the control $(0 \mu \mathrm{g} / \mathrm{mL}$, Figure S7), and a higher number of cells was observed over time. Only EE-S (Figure S10) and HE-T (Figure S12) at 125 and $250 \mu \mathrm{g} / \mathrm{mL}$, respectively, drastically changed the fibroblast's morphology, whereby a lower number of fibroblasts were observed and having a more rounded-like shape.

AE-S were significantly more cytotoxic in comparison with AE-T. Contrarily, HE-S was more cytocompatible in comparison with HE-T. Analyzing all the S. officinalis extracts, the L929 cell line was more cytocompatible with AE-T, followed by AE-S, HE-S, HE-T, and EE-S.

\subsubsection{Non- and LPS-Stimulated Macrophages}

The metabolic activity and relative DNA concentration obtained for nonstimulated macrophages (Figure 6) and LPS-stimulated macrophages (Figure 7) in the absence or presence of the S. officinalis extracts at different concentrations are similar, except for the highest tested concentration $(250 \mu \mathrm{g} / \mathrm{mL})$ for EE-S. The DNA of macrophages was preserved in the presence of the different $S$. officinalis extracts (Figure 6B) and under an inflammatory scenario (Figure 7B). Only the EE-S in the highest concentration $(250 \mu \mathrm{g} / \mathrm{mL})$ significantly reduced the DNA concentration of nonstimulated macrophages, which was even more pronounced in LPS-stimulated macrophages, which is in agreement with metabolic activity results. No significant differences were observed between extraction techniques.
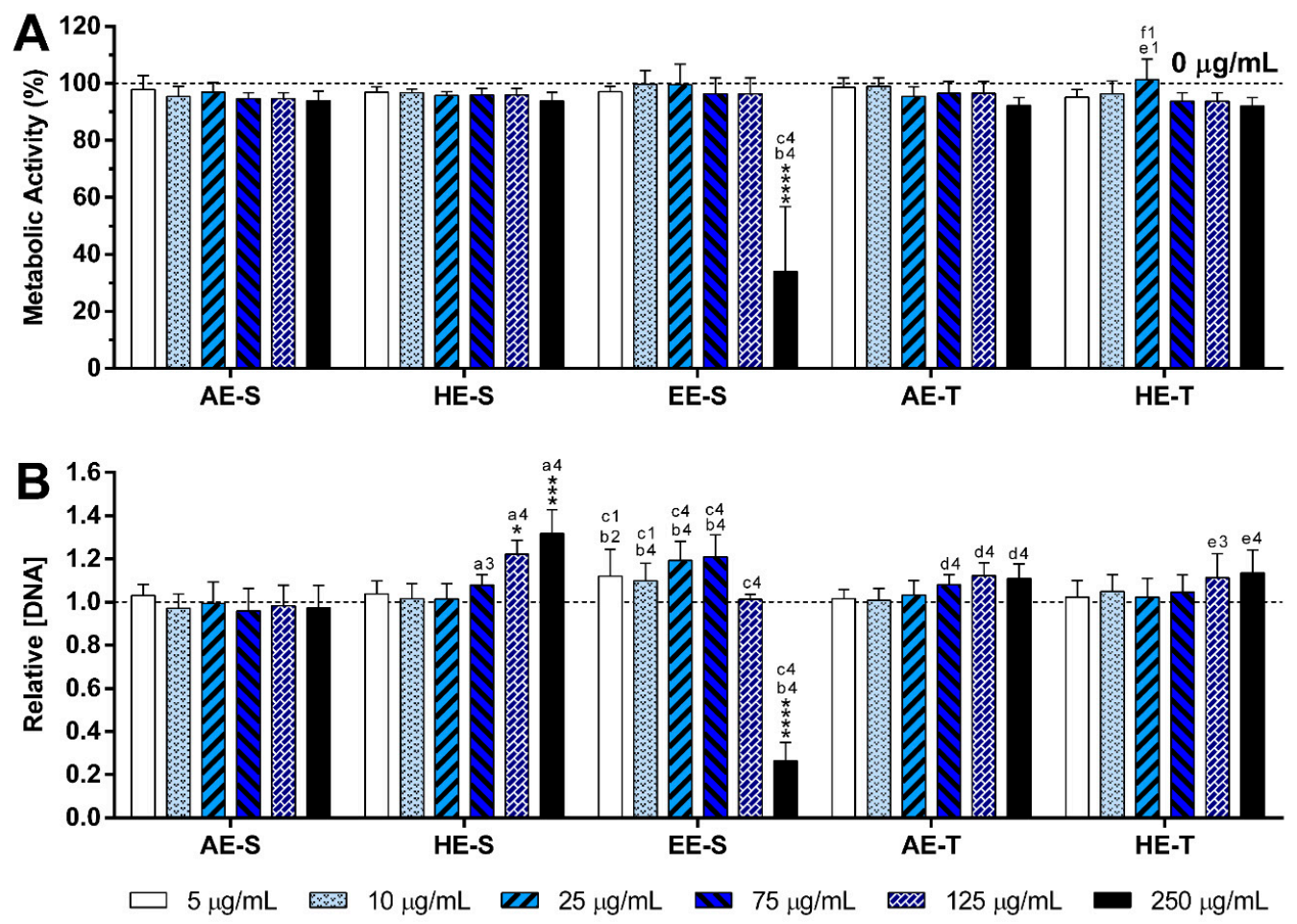

Figure 6. Metabolic activity (A) and relative DNA concentration (B) of nonstimulated macrophages cultured in the presence of different concentrations of the Salvia officinalis extracts for $24 \mathrm{~h}$ of culture at $37^{\circ} \mathrm{C}$. The dotted line represents the nontreated condition $(0 \mu \mathrm{g} / \mathrm{mL})$ for each assay. Statistically significant differences are ${ }^{*}(p<0.0384),{ }^{* * *}(p<0.00109)$ and ${ }^{* * *}(p<0.0001)$ in comparison to the negative control $(0 \mu \mathrm{g} / \mathrm{mL})$ for each different tested extract, and $1(p<0.0251), 2(p<0.095), 3(p<0.0005)$, and $4(p<0.0001)$ in comparison with a (AE-S vs. HE-S), b (AE-S vs. EE-S), c (HE-S vs. EE-S), d (AE-S vs. AE-T), e (HE-S vs. HE-T), and f (AE-T vs. HE-T). AE: aqueous extracts; HE: hydroethanolic extracts; EE: ethanolic extracts; S: soxhlet extraction; T: traditional extraction. 

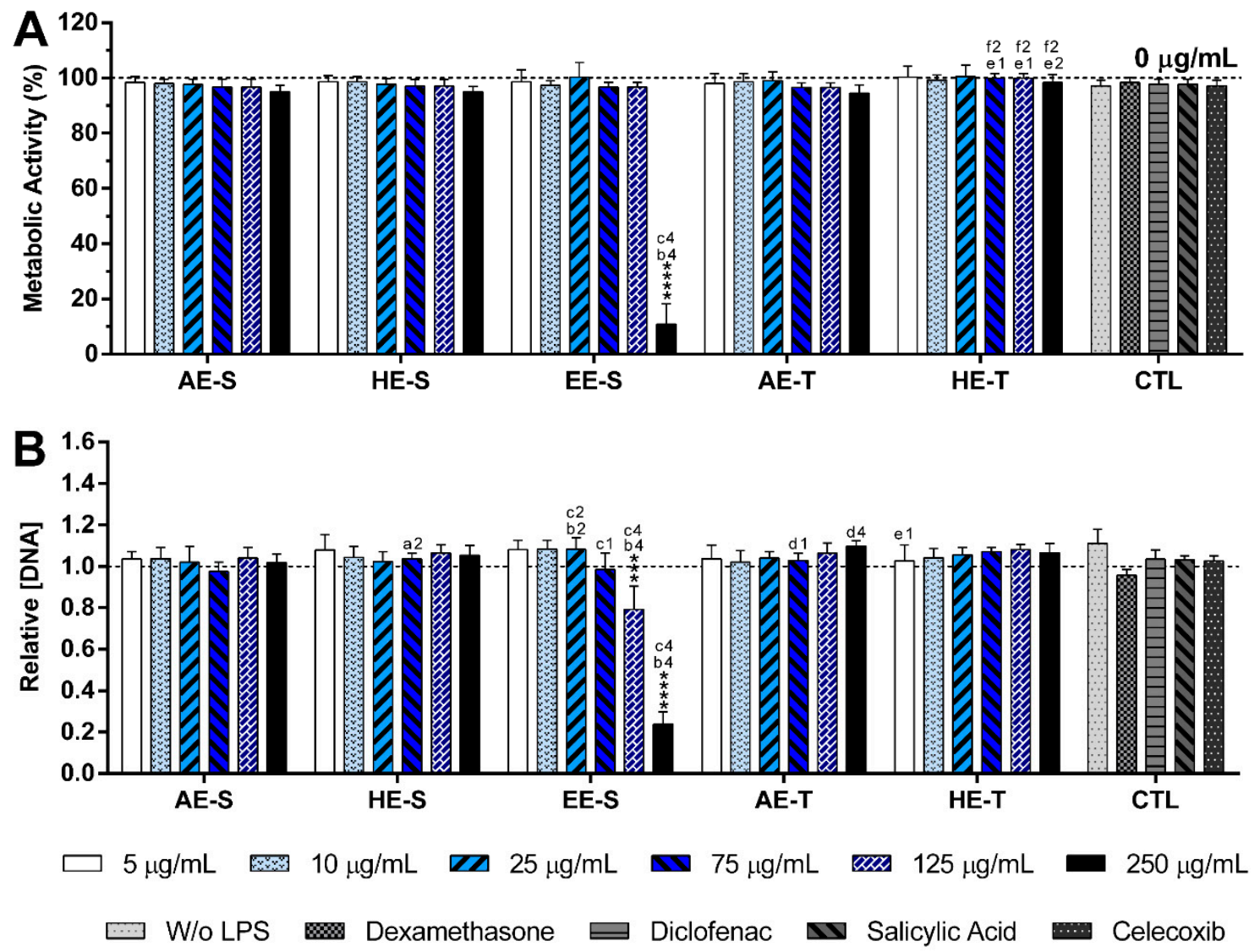

Figure 7. Metabolic activity (A) and relative DNA concentration (B) of LPS-stimulated macrophages cultured in the presence of different concentrations of the Salvia officinalis extracts and clinically used anti-inflammatory drugs (dexamethasone, diclofenac, salicylic acid and celecoxib, $10 \mu \mathrm{M}$ ) for $24 \mathrm{~h}$ of culture at $37^{\circ} \mathrm{C}$. The dotted line represents the nontreated condition $(0 \mu \mathrm{g} / \mathrm{mL})$ for each assay. Statistically significant differences are ${ }^{* * *}(p<0.0006)$ and ${ }^{* * * *}(p<0.0001)$ in comparison to the negative control $(0 \mu \mathrm{g} / \mathrm{mL})$ for each different tested extract, and $1(p<0.0376), 2(p<0.0090)$, and $4(p<0.0001)$ in comparison with a (AE-S vs. HE-S), b (AE-S vs. EE-S), c (HE-S vs. EE-S), d (AE-S vs. AE-T), e (HE-S vs. HE-T), and f (AE-T vs. HE-T). AE: aqueous extracts; HE: hydroethanolic extracts; EE: ethanolic extracts; S: soxhlet extraction; T: traditional extraction; CTL: control.

Optical micrographs of nonstimulated macrophages (Figures S14 and S15) and LPS-stimulated macrophages (Figures S16 and S17) confirmed that the cell morphology was not affected by the different S. officinalis extracts at different concentrations. All the tested conditions showed a macrophage-like-phenotype similar to the negative control $(0 \mu \mathrm{g} / \mathrm{mL}$, Figure S13) in all tested conditions. However, the morphology of macrophages was only drastically affected by the presence of EE-S for concentrations higher than $125 \mu \mathrm{g} / \mathrm{mL}$ (Figures S14 and S16). These results are in agreement with previous assays.

\subsection{Pro- and Anti-Inflammatory Activity of S. officinalis Extracts}

\subsubsection{Nonstimulated Macrophages}

The proinflammatory activity of cytocompatible $S$. officinalis extracts was evaluated by assessing the levels of IL- 6 and TNF- $\alpha$ produced by non-LPS-stimulated macrophages in the cell culture medium. Nonstimulated macrophages without treatment $(0 \mu \mathrm{g} / \mathrm{mL}$, negative control $)$ did not produce measurable amounts of IL- 6 but produced small amounts of TNF- $\alpha(2.8 \pm 2.0 \mathrm{pg} / \mathrm{mL})$. Indeed, the production of basal levels of proinflammatory cytokines has been reported for macrophages [54]. When macrophages 
were incubated with $S$. officinalis extracts at different concentrations, a significant increase of the IL-6 and TNF- $\alpha$ levels was not observed in the culture medium.

\subsubsection{LPS-Stimulated Macrophages}

The stimulation of macrophages with LPS $(100 \mathrm{ng} / \mathrm{mL})$ led to a significant production of IL-6 and TNF- $\alpha$ (Figure 8 ), which is not observed in nonstimulated macrophages, as previously verified.
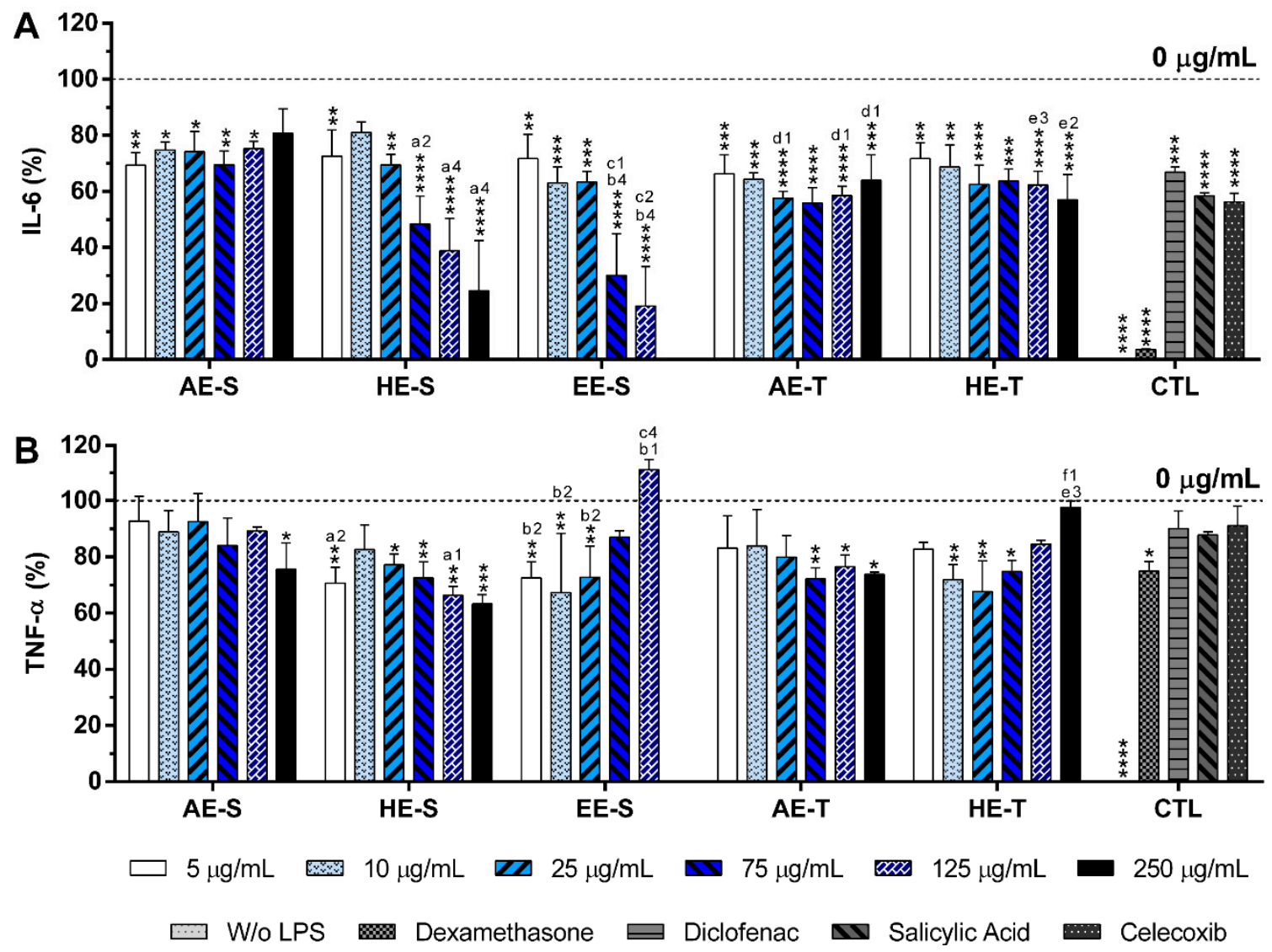

Figure 8. IL-6 (A) and TNF- $\alpha$ (B) percentages of LPS-stimulated macrophages cultured in the presence of different concentrations of the Salvia officinalis extracts and clinically used anti-inflammatory drugs (dexamethasone, diclofenac, salicylic acid, and celecoxib, $10 \mu \mathrm{M}$ ) for $24 \mathrm{~h}$ of culture at $37^{\circ} \mathrm{C}$. The dotted line represents the nontreated condition $(0 \mu \mathrm{g} / \mathrm{mL})$ for each assay. Statistically significant differences are $^{*}(p<0.0474),{ }^{* *}(p<0.0092),{ }^{* *}(p<0.0008),{ }^{* * *}(p<0.0001)$ in comparison to the positive control $(0 \mu \mathrm{g} / \mathrm{mL})$ for each different tested extracted, and 1 ( $p<0.0381), 2(p<0.0085), 3(p<0.0009)$, and 4 $(p<0.0001)$ in comparison with a (AE-S vs. HE-S), b (AE-S vs. EE-S), c (HE-S vs. EE-S), d (AE-S vs. AE-T), e (HE-S vs. HE-T), and f (AE-T vs. HE-T). AE: aqueous extracts; HE: hydroethanolic extracts; EE: ethanolic extracts; S: soxhlet extraction; T: traditional extraction; CTL: control.

Dexamethasone, diclofenac, salicylic acid, or celecoxib at $10 \mu \mathrm{M}$ led to a statistically significant reduction of IL- 6 production by $96.4 \pm 0.2 \%, 33.1 \pm 1.8 \%, 41.6 \pm 1.2 \%$, and $43.7 \pm 3.1 \%$, respectively, being the first and most efficient control. In the presence of all S. officinalis extracts, IL-6 production was also statistically significantly reduced. S. officinalis extracts obtained from soxhlet extraction were more efficient in the reduction of IL-6 production than the extracts obtained from traditional extraction. Treatment with HE-S and EE-S drastically decreased the IL-6 production in a concentration-dependent manner. HE-S and EE-S, at a cytocompatible concentration $(75 \mu \mathrm{g} / \mathrm{mL})$, decreased the IL-6 production by $51.6 \pm 10.0 \%$ and $70.0 \pm 14.9 \%$, respectively. In the case of the AE-S, AE-T, and HE-T, the influence of the extract concentration in the reduction of the IL-6 production was observed. A small concentration 
$(75 \mu \mathrm{g} / \mathrm{mL})$ of AE-S and AE-T were required to inhibit $30.5 \pm 5.0$ and $44.2 \pm 5.5 \%$ of IL-6 production, respectively. HE-T could reduce $37.7 \pm 4.9 \%$ of IL-6 production with a concentration of $125 \mu \mathrm{g} / \mathrm{mL}$. Analyzing all the $S$. officinalis extracts, the reduction of IL-6 production was more pronounced with EE-S, followed by HE-S, HE-T, AE-T, and AE-S.

Dexamethasone $(10 \mu \mathrm{M})$ significantly reduced TNF- $\alpha$ production by a percentage of $25.0 \pm 3.3 \%$. Under this in vitro inflammatory model, a reduction of $9.9 \pm 6.3 \%, 12.2 \pm 1.2 \%$, and $8.9 \pm 6.9 \%$ of the TNF- $\alpha$ amount was obtained for diclofenac, salicylic acid, and celecoxib at $10 \mu \mathrm{M}$, respectively, but no significant differences were observed (Figure 8B). Conversely, S. officinalis extracts were able to significantly reduce the TNF- $\alpha$ amount. The efficacy of extracts to reduce TNF- $\alpha$ production was not influenced by the extraction technique. AE-T were more efficient in the reduction of this proinflammatory cytokine in comparison with AE-S, while HE-S showed more anti-inflammatory activity than HE-T. HE-S, at $250 \mu \mathrm{g} / \mathrm{mL}$, led to the higher reduction of the TNF- $\alpha$ amount $(36.7 \pm 3.4 \%)$, even if compared with all the tested controls. A similar reduction of this cytokine was observed for EE-S $(32.7 \pm 21.1 \%$ at $10 \mu \mathrm{g} / \mathrm{mL})$ and HE-T $(32.2 \pm 10.8 \%$, at $25 \mu \mathrm{g} / \mathrm{mL})$ at lower concentrations AE-TE $(75 \mu \mathrm{g} / \mathrm{mL})$ and AE-S $(250 \mu \mathrm{g} / \mathrm{mL})$ also led to a significant reduction of TNF- $\alpha$ production by $27.8 \pm 3.9 \%$ and $24.4 \pm 9.3 \%$, respectively.

\section{Discussion}

Powerful benefits of S. officinalis were reported already by the Romans; its leaves were considered as a medicine to enhance health and treat ailments, especially in inflammatory disorders [32]. Inspired by this, S. officinalis leaves were used to obtain new extracts with the ability to treat inflammatory diseases. In the literature, the most frequently used extraction solvents for S. officinalis are water, methanol, ethanol, acetone, hexane, and ethyl acetate, resulting in extracts enriched in phenols (carnosic acid, carnosol, methyl carnosate, rosmarinic acid, rosmanol, rosmadial, epirosmanol, caffeic acid, ferulic acid), flavonoids (apigenin, apigenin 7-O-glucoside, luteolin, luteolin-7-O-glucoside, luteolin 7-O-glucuronide), and essential oils (1,8-cineole, $\alpha / \beta$-thujone, camphor, camphene, borneol, bornyl acetate, $\beta$-pinene, manool, viridiflorol [55-64]. In this work, the process of extraction was first and exactly carried as it has been traditionally performed for years. In this sense, AE-T and HE-T were obtained by infusion and maceration, respectively. A soxhlet apparatus was then used to obtain these two types of extracts (AE-S and HE-S), as well as EE-S. Indeed, the efficiency of extraction can be affected by several parameters, such as the chemical nature of the bioactive compounds, extraction method, weight and size of the plant samples, as well as solvent, $\mathrm{pH}$, time, and temperature of extraction [65]. Therefore, as expected, in this work, the extraction yield was strongly influenced by the extraction technique and the solvent used (Figure 1A). Soxhlet extraction provided higher efficiency $(\approx 50 \%)$ than traditional extraction in the recovery of hydrophilic compounds from S. officinalis, since the combination of water with heating for longer periods of time promoted more efficient cell disruption, increasing the extraction capacity [66]. In maceration, the contact between the plant sample and solvent was maintained for five days, which promoted a similar amount of extractable hydroethanolic compounds in comparison with the soxhlet extraction.

Regarding TPC, S. officinalis is the species of Salvia that presents the highest content of phenolic compounds [67]. The amount of phenolic compounds (Figure 1B) was significantly higher in the soxhlet extraction than in the traditional extraction, whereas the amount of flavonoid compounds (Figure 1C) was higher in hydroethanolic extracts compared to the other types of extracts. These results emphasize the important role of the temperature and polarity of the solvent in both phenol and flavonoid extraction, respectively. Although the extraction yield did not present statistically significant differences between AE-S and HE-S and between HE-S and HE-T, their TPC was statistically different. This observation emphasizes that other compounds behind phenols (and flavonoids), such as proteins, carbohydrates, and polysaccharides, have been extracted from S. officinalis leaves, contributing, therefore, to enhancing its extraction yield. There are different studies reporting the TPC of several S. officinalis or other plant species extracts, prepared with different extraction techniques $[54,57,63,68-70]$. The TPC and TFC of 
the S. officinalis extracts obtained in this study were significantly higher than the values obtained for similar ethyl acetate extracts produced by Kontogianni et al. [40]. As both extracts were prepared with a soxhlet, the selection of solvents may be the main responsible for these differences in phenols and flavonoids amounts.

According to TLC analysis, rosmarinic acid, carnosol, and carnosic acid are present in S. officinalis extracts (Figure 2). Rosmarinic acid was presented in all extracts, meaning that the solvent and technique of extraction did not affect its recovery. Rosmarinic acid was also detected by TLC in AE and HE obtained by the traditional method [71,72]. To extract carnosol and carnosic acid (HE-S and EE-E), high temperatures and the presence of ethanol in the solvent of extraction were required.

Phenolic and flavonoid compounds, such as rosmarinic acid, carnosol, and carnosic acid present antioxidant activity $[58,73,74]$. Therefore, the antioxidant ability of $S$. officinalis extracts against DPPH ${ }^{\bullet}$ and $\mathrm{ABTS}^{\bullet+}$ (Figure 3), as well as $\mathrm{ROO}^{\bullet},{ }^{\bullet} \mathrm{NO}$, and $\mathrm{O}_{2}{ }^{\bullet-}$ and reducing power (Figure 4), were all evaluated. Overall, depending on the assayed extracts and reactive species, all S. officinalis extracts exhibited significant antioxidant activity (Figures S1-S5). They were also able to reduce the ferric form $\left(\mathrm{Fe}^{3+}\right)$ into ferrous $\left(\mathrm{Fe}^{2+}\right)$ in a concentration-dependent manner (Figure S6). This demonstrates the phytochemical compounds' ability to donate a hydrogen atom and neutralize the radicals [42-45,47,48]. The differences in the activities among the different extracts could be related to the extracts' composition and the relative amount of certain compounds. Lu et al. demonstrated that $S$. officinalis phenols are more powerful in scavenging DPPH ${ }^{\bullet}$ than flavonoids, which have only weak to moderate activities [74]. Rosmarinic acid was detected in all S. officinalis extracts, and carnosic acid is present in HE-S and EE-S. Those compounds have two catechol groups in the aromatic ring of the phenolic skeleton, presenting a strong antioxidant activity [57]. Other compounds, such as caffeoyl derivatives, with a chemical structure similar to rosmarinic acid, are also abundant in Lamiaceae species and can contribute to the antioxidant activity of the extracts [57]. Indeed, the antioxidant properties of single compounds within a group can vary remarkably so that the same levels of phenolic compounds do not correspond to the same antioxidant responses [75]. Moreover, some phenolic compounds cannot be quantified by the Folin-Ciocalteu method [75], whereby the radical scavenging activity of an extract cannot be deduced only by its TPC. In fact, the relationship between yield extraction, TPC, and its antioxidant activity is not always closely correlated [29]. For instance, methanol/water extracts obtained by stirring showed higher antiradical activity against $\mathrm{DPPH}^{\bullet}$ than $\mathrm{AE}$ (decoction). However, the latter presented the highest concentration in phenolic and flavonoids compounds [56]. Moreover, HE produced in an enamel boiler by Kozics et al. demonstrated higher antiradical activity against $\mathrm{DPPH}^{\bullet}$ and $\mathrm{ABTS} \mathrm{\bullet}^{\bullet+}$ than the S. officinalis extracts herein tested [76]. These differences can arise from the different extraction techniques and the experimental conditions used in the antiradical assay. A similar result was observed for extracts prepared in a soxhlet apparatus, but with an $\mathrm{IC}_{50}$ two times lower than the values obtained for the extracts herein studied [40]. In this case, the assay was performed in the same way, highlighting the importance of the extraction solvents in the biological activity of the extract. The authors started the extraction of leaves with hexane, followed by ethyl acetate. The hexane may remove compounds with no biological activity, while ethyl acetate may concentrate them. Interestingly, there are few studies reporting the antioxidant activity of $S$. officinalis extracts against $\mathrm{ROO} \bullet,{ }^{\bullet} \mathrm{NO}$, and $\mathrm{O}_{2}{ }^{\bullet-}$. A mixture of flowers, leaves, and stems of $S$. officinalis was extracted by decoction and defatted with n-hexane [77]. These extracts presented around two times more antioxidant activity against $\mathrm{O}_{2}^{\bullet-}$, while similar antioxidant activity against ${ }^{\bullet} \mathrm{NO}$ is observed. Again, these results show the importance of the solvent in the extraction of the biologically active compounds, as well as the interference of the different parts of plants.

Soxhlet extracts were more powerful scavengers for all the tested radicals (lower $\mathrm{IC}_{50}$ ) compared with their counterparts obtained in traditional extracts, which could be related to the higher TPC and TFC. However, the most pronounced antioxidant effect was observed for AE-S, since they have the lowest $\mathrm{IC}_{50}$ for all tested radicals. Moreover, these extracts present antioxidant activity against $\bullet \mathrm{NO}$, which is not observed for AE-T. The antioxidant activity against $\mathrm{O}_{2}{ }^{\bullet-}$ was also higher for these 
extracts in comparison with HE-T. Conversely, EE-S exhibited the lowest antioxidant activity. Similar to our results, an ethanolic extract of Mentha rotundifolia exhibited the lowest TPC; however, it was the most effective in the protection of lipid and protein peroxidation in the cell membrane of red blood cells than Mentha pulegium extract with higher TPC [54]. Therefore, during an inflammatory response, AE-S can neutralize the reactive molecules $[2,3,10]$, terminate free-radical chain reactions (e.g., lipid peroxidation) by converting free radicals to more stable products [10], and ameliorate, e.g., the vascular permeability of the inflamed tissues, reducing the extravasation of immune cells [3]. Consequently, a cascade of reactions that lead to inflammatory and degenerative diseases, could be prevented. However, as $S$. officinalis extracts are also good electron donors, excess of antioxidant compounds in the presence of free metal ions, such as $\mathrm{Fe}$ or $\mathrm{Cu}$, can also initiate and promote free radicals' reactions and, consequently, an undesired pro-oxidative effect can be obtained $[10,78]$. Nonetheless, the oxidized forms of $S$. officinalis extracts may be relatively unreactive, and, consequently, do not cause cellular damage. In general, AE were more cytocompatible with the L929 cell line, whereas EE-S must have cytotoxic compounds for these fibroblasts (Figure 5A). Moreover, within the range of cytocompatible concentrations, fibroblasts were able to proliferate (Figure 5B) and synthesize proteins (Figure 5C) for $72 \mathrm{~h}$ of culture. Interestingly, some $S$. officinalis extracts were able to stimulate the mitogenic activity and protein synthesis, mainly AE, since higher amounts of DNA and protein concentration were observed in comparison with control $(0 \mu \mathrm{g} / \mathrm{mL})$. This effect can be related to the cytoprotective effect of S. officinalis extracts due to their antioxidant activity [54]. Furthermore, a fibroblast-like-phenotype was observed for S. officinalis extracts at cytocompatible concentrations (Figures S7-S12). These results are in agreement with the data of metabolic activity, relative DNA, and total protein concentrations obtained.

The immunomodulatory activity of $S$. officinalis extracts was assessed using macrophages since they are key players of the immune system [79]. To model an inflammatory scenario, macrophages were activated in vitro with LPS, which triggers a cascade of inflammatory pathways, including the induction of the production of proinflammatory cytokines (e.g., IL-6 and TNF- $\alpha$ ) and ROS/RNS [80]. S. officinalis extracts were cytocompatible with both nonstimulated (Figure 6, Figures S14 and S15) and LPS-stimulated macrophages (Figure 7, Figures S16 and S17). Only EE-S in the highest tested concentration $(250 \mu \mathrm{g} / \mathrm{mL})$ significantly affected the macrophages' metabolic activity, DNA concentration, and morphology, demonstrating its cytotoxicity if present in high amounts.

None of the $S$. officinalis extracts showed the ability to induce the production by nonstimulated macrophages of the proinflammatory cytokines IL-6 and TNF- $\alpha$, suggesting that they lack immunostimulatory activity over macrophages. Conversely, our results indicated that all five S. officinalis extracts at cytocompatible concentrations efficiently reduced IL- 6 and TNF- $\alpha$ production by LPS-stimulated macrophages (Figure 8). A comparable reduction of the IL- 6 and TNF- $\alpha$ production was also observed in the oxidized low-density lipoproteins (ox-LDL) simulated macrophages (THP-1 cell line) in the presence of supercritical S. officinalis extracts [81]. The traditional extraction provided the AE with stronger anti-inflammatory activity in the reduction of IL- 6 and TNF- $\alpha$ production. In fact, traditional extraction can retain the volatile components of $S$. officinalis, while they may be lost in a soxhlet extraction. These volatile compounds, such as camphor and borneol, reportedly have anti-inflammatory activity [34,37]. When the extracts were prepared using HE, the soxhlet originated stronger anti-inflammatory extracts, suggesting that this extraction technique recovered more compounds with the ability to reduce the IL-6 and TNF- $\alpha$ production, such as rosmarinic acid, carnosic acid, and carnosol [82-84]. Interestingly, EE-S was the most powerful anti-inflammatory extract that should be strongly related to the presence of rosmarinic acid, carnosol, and carnosic acid, followed by HE-S (presence of rosmarinic acid, carnosol, and carnosic acid) and AE-S (presence of rosmarinic acid). This result pointed out that solvent selection is extremely important to recover extracts with strong activity in reducing inflammatory cytokines production. Indeed, this highlights that the quality of the bioactive compounds that comprise the extract strongly influenced its biological activities.

A reduction of IL-6 production in a concentration-dependent manner was observed for both HE-S and EE-S, whereas the reduction of TNF- $\alpha$ in a concentration-dependent manner was only detected 
when macrophages were cultured in the presence of HE-S. A low amount of S. officinalis extracts (AE-S, AE-T, and HE-T, $5 \mu \mathrm{g} / \mathrm{mL}$ ) was able to reduce IL-6 production. Moreover, at cytocompatible concentrations $(75 \mu / \mathrm{mL})$, the $S$. officinalis extracts were able to attenuate the TNF- $\alpha$ production by LPS-stimulated macrophages. Indeed, S. officinalis extracts led to a similar or higher decrease of the IL-6 and TNF- $\alpha$ amount than the well-known tested NSAIDs, namely diclofenac, salicylic acid, and celecoxib. Additionally, EE-S and HE-S showed similar anti-inflammatory activities of dexamethasone, a potent corticosteroid, but with important side effects. Thus, a formulation of $S$. officinalis extracts can be a promising therapeutic strategy for the reduction of the inflammatory process.

\section{Conclusions}

The present study showed that the selection of solvents and extraction techniques should be carefully considered since they influence the bioactivity and toxicity of the obtained extracts. AE-S obtained from S. officinalis leaves, enriched in phenols (e.g., rosmarinic acid) and flavonoids, showed to contain the best antioxidant mixture against dangerous free radicals. However, EE-S, with the lowest antioxidant activity, was the most promising extract in the reduction of IL- 6 and TNF- $\alpha$ production by human macrophages, suggesting that rosmarinic acid, carnosol, and carnosic acid may be responsible for this activity. These results proved that $S$. officinalis leaves contain valuable substances. Therefore, a formulation combining, for instance, AE-S and EE-S would be a strong and promising antioxidant and anti-inflammatory mixture to counteract chronic inflammatory pathways, probably with low side effects. Therefore, $S$. officinalis extracts can be used as an effective and safe source of new drugs to treat chronic inflammatory diseases. Further in-depth studies are required to specifically determine which compounds present in S. officinalis extracts may really contribute to antioxidant and anti-inflammatory activities.

Supplementary Materials: The following are available online at http://www.mdpi.com/2076-3921/9/11/1157/s1.

Author Contributions: Conceptualization, S.F.V., H.F., and N.M.N.; methodology, S.F.V., H.F., and N.M.N.; validation, S.F.V., H.F., and N.M.N.; formal analysis, S.F.V.; investigation, S.F.V.; resources, S.F.V., H.F., and N.M.N.; data curation, S.F.V.; writing-original draft preparation, S.F.V.; writing-review and editing, H.F. and N.M.N.; visualization, S.F.V.; supervision, H.F. and N.M.N.; project administration, N.M.N.; funding acquisition, H.F. and N.M.N. All authors have read and agreed to the published version of the manuscript.

Funding: This research was funded by the Fundação para a Ciência e a Tecnologia (FCT) to the PhD grant of SV (PD/BD/135246/2017) and the projects PATH (PD/00169/2013), Cells4_IDs (PTDC/BTM-SAL/28882/2017) and the NORTE 2020 Structured Project, cofunded by Norte2020 (NORTE-01-0145-FEDER-000021).

Conflicts of Interest: The authors declare no conflict of interest.

\section{References}

1. Medzhitov, R. Origin and physiological roles of inflammation. Nature 2008, 454, 428. [CrossRef] [PubMed]

2. Mittal, M.; Siddiqui, M.R.; Tran, K.; Reddy, S.P.; Malik, A.B. Reactive oxygen species in inflammation and tissue injury. Antioxid. Redox Signal. 2014, 20, 1126-1167. [CrossRef] [PubMed]

3. Martinez, M.C.; Andriantsitohaina, R. Reactive nitrogen species: Molecular mechanisms and potential significance in health and disease. Antioxid. Redox Signal. 2009, 11, 669-702. [CrossRef] [PubMed]

4. El-Benna, J.; Hurtado-Nedelec, M.; Marzaioli, V.; Marie, J.-C.; Gougerot-Pocidalo, M.-A.; Dang, P.M.-C. Priming of the neutrophil respiratory burst: Role in host defense and inflammation. Immunol. Rev. 2016, 273, 180-193. [CrossRef] [PubMed]

5. Iles, K.E.; Forman, H.J. Macrophage signaling and respiratory burst. Immunol. Res. 2002, 26, 95-105. [CrossRef]

6. Morgan, M.J.; Liu, Z. Crosstalk of reactive oxygen species and NF-kB signaling. Cell Res. 2011, 21, $103-115$. [CrossRef]

7. Forrester, S.J.; Kikuchi, D.S.; Hernandes, M.S.; Xu, Q.; Griendling, K.K. Reactive Oxygen Species in Metabolic and Inflammatory Signaling. Circ. Res. 2018, 122, 877-902. [CrossRef]

8. Hunter, C.A.; Jones, S.A. IL-6 as a keystone cytokine in health and disease. Nat. Immunol. 2015, 16, 448. [CrossRef] 
9. Brenner, D.; Blaser, H.; Mak, T.W. Regulation of tumour necrosis factor signalling: Live or let die. Nat. Rev. Immunol. 2015, 15, 362-374. [CrossRef]

10. Halliwell, B. Reactive oxygen species in living systems: Source, biochemistry, and role in human disease. Am. J. Med. 1991, 91, S14-S22. [CrossRef]

11. Chitnis, T.; Weiner, H.L. CNS inflammation and neurodegeneration. J. Clin. Investig. 2017, 127, 3577-3587. [CrossRef] [PubMed]

12. Abou-Raya, S.; Abou-Raya, A.; Naim, A.; Abuelkheir, H. Chronic inflammatory autoimmune disorders and atherosclerosis. Ann. N. Y. Acad. Sci. 2007, 1107, 56-67. [CrossRef] [PubMed]

13. Chen, H.; He, Y.; Chen, S.; Qi, S.; Shen, J. Therapeutic targets of oxidative/nitrosative stress and neuroinflammation in ischemic stroke: Applications for natural product efficacy with omics and systemic biology. Pharmacol. Res. 2020, 158, 104877. [CrossRef] [PubMed]

14. Steinmeyer, J. Pharmacological basis for the therapy of pain and inflammation with nonsteroidal anti-inflammatory drugs. Arthritis Res. 2000, 2, 379-385. [CrossRef]

15. Barnes, P.J. How corticosteroids control inflammation: Quintiles Prize Lecture 2005. Br. J. Pharmacol. 2006, 148, 245-254. [CrossRef]

16. Baumgart, D.C.; Misery, L.; Naeyaert, S.; Taylor, P.C. Biological Therapies in Immune-Mediated Inflammatory Diseases: Can Biosimilars Reduce Access Inequities? Front. Pharmacol. 2019, 10, 279. [CrossRef]

17. Harirforoosh, S.; Jamali, F. Renal adverse effects of nonsteroidal anti-inflammatory drugs. Expert Opin. Drug Saf. 2009, 8, 669-681. [CrossRef]

18. Sostres, C.; Gargallo, C.J.; Arroyo, M.T.; Lanas, A. Adverse effects of non-steroidal anti-inflammatory drugs (NSAIDs, aspirin and coxibs) on upper gastrointestinal tract. Best Pract. Res. Clin. Gastroenterol. 2010, 24, 121-132. [CrossRef]

19. Patrono, C. Cardiovascular Effects of Nonsteroidal Anti-inflammatory Drugs. Curr. Cardiol. Rep. 2016, 18, 25. [CrossRef]

20. Chamoun-Emanuelli, A.M.; Bryan, L.K.; Cohen, N.D.; Tetrault, T.L.; Szule, J.A.; Barhoumi, R.; Whitfield-Cargile, C.M. NSAIDs disrupt intestinal homeostasis by suppressing macroautophagy in intestinal epithelial cells. Sci. Rep. 2019, 9, 14534. [CrossRef]

21. Buchman, A.L. Side Effects of Corticosteroid Therapy. J. Clin. Gastroenterol. 2001, 33, 289-294. [CrossRef] [PubMed]

22. Swart, J.F.; de Roock, S.; Wulffraat, N.M. What are the immunological consequences of long-term use of biological therapies for juvenile idiopathic arthritis? Arthritis Res. Ther. 2013, 15, 213. [CrossRef] [PubMed]

23. Shivaji, U.N.; Sharratt, C.L.; Thomas, T.; Smith, S.C.L.; Iacucci, M.; Moran, G.W.; Ghosh, S.; Bhala, N. Review article: Managing the adverse events caused by anti-TNF therapy in inflammatory bowel disease. Aliment. Pharmacol. Ther. 2019, 49, 664-680. [CrossRef] [PubMed]

24. WHO (World Health Organization). The World Traditional Medicines Situation, in Traditional Medicines: Global Situation, Issues and Challenges, 3rd ed.; WHO: Geneva, Switzerland, 2011.

25. Fabricant, D.S.; Farnsworth, N.R. The value of plants used in traditional medicine for drug discovery. Environ. Health Perspect. 2001, 109, 69-75. [CrossRef] [PubMed]

26. Farnsworth, N.R.; Akerele, O.; Bingel, A.S.; Soejarto, D.D.; Guo, Z. Medicinal plants in therapy. Bull. World Health Organ. 1985, 63, 965-981. [CrossRef]

27. Patridge, E.; Gareiss, P.; Kinch, M.S.; Hoyer, D. An analysis of FDA-approved drugs: Natural products and their derivatives. Drug Discov. Today 2016, 21, 204-207. [CrossRef]

28. Gasparrini, M.; Giampieri, F.; Forbes-Hernandez, T.Y.; Afrin, S.; Cianciosi, D.; Reboredo-Rodriguez, P.; Varela-Lopez, A.; Zhang, J.; Quiles, J.L.; Mezzetti, B.; et al. Strawberry extracts efficiently counteract inflammatory stress induced by the endotoxin lipopolysaccharide in Human Dermal Fibroblast. Food Chem. Toxicol. 2018, 114, 128-140. [CrossRef]

29. Kuo, X.; Herr, D.R.; Ong, W.-Y. Anti-inflammatory and Cytoprotective Effect of Clinacanthus nutans Leaf But Not Stem Extracts on 7-Ketocholesterol Induced Brain Endothelial Cell Injury. Neuromol. Med. 2020. [CrossRef]

30. Newman, D.J.; Cragg, G.M. Natural Products as Sources of New Drugs from 1981 to 2014. J. Nat. Prod. 2016, 79, 629-661. [CrossRef]

31. Harvey, A.L. Natural products in drug discovery. Drug Discov. Today 2008, 13, 894-901. [CrossRef]

32. Brown, O.P. The Complete Herbalist: Newcastle Classic Series; Newcastle Pub.: Jesery, UK, 1897; ISBN 9780878771844. 
33. Neves, J.M.; Matos, C.; Moutinho, C.; Queiroz, G.; Gomes, L.R. Ethnopharmacological notes about ancient uses of medicinal plants in Tras-os-Montes (northern of Portugal). J. Ethnopharmacol. 2009, 124, 270-283. [CrossRef] [PubMed]

34. Ehrnhofer-Ressler, M.M.; Fricke, K.; Pignitter, M.; Walker, J.M.; Walker, J.; Rychlik, M.; Somoza, V. Identification of 1,8-cineole, borneol, camphor, and thujone as anti-inflammatory compounds in a Salvia officinalis L. infusion using human gingival fibroblasts. J. Agric. Food Chem. 2013, 61, 3451-3459. [CrossRef] [PubMed]

35. Li, L.; Wei, S.; Zhu, T.; Xue, G.; Xu, D.; Wang, W.; Wang, X.; Luo, J.; Kong, L. Anti-inflammatory norabietane diterpenoids from the leaves of Salvia officinalis L. J. Funct. Foods 2019, 54, 154-163. [CrossRef]

36. Lima, C.F.; Andrade, P.B.; Seabra, R.M.; Fernandes-Ferreira, M.; Pereira-Wilson, C. The drinking of a Salvia officinalis infusion improves liver antioxidant status in mice and rats. J. Ethnopharmacol. 2005, 97, 383-389. [CrossRef]

37. Rodrigues, M.R.A.; Kanazawa, L.K.S.; das Neves, T.L.M.; da Silva, C.F.; Horst, H.; Pizzolatti, M.G.; Santos, A.R.S.; Baggio, C.H.; Werner, M.F. de P. Antinociceptive and anti-inflammatory potential of extract and isolated compounds from the leaves of Salvia officinalis in mice. J. Ethnopharmacol. 2012, 139, 519-526. [CrossRef]

38. International Organization for Standardization. ISO 10993-5:2009-Biological Evaluation of Medical Devices-Part 5: Tests for in Vitro Cytotoxicity; ISO: Geneva, Switzerland, 2009.

39. Luque de Castro, M.D.; Priego-Capote, F. Soxhlet extraction: Past and present panacea. J. Chromatogr. A 2010, 1217, 2383-2389. [CrossRef]

40. Kontogianni, V.G.; Tomic, G.; Nikolic, I.; Nerantzaki, A.A.; Sayyad, N.; Stosic-Grujicic, S.; Stojanovic, I.; Gerothanassis, I.P.; Tzakos, A.G. Phytochemical profile of Rosmarinus officinalis and Salvia officinalis extracts and correlation to their antioxidant and anti-proliferative activity. Food Chem. 2013, 136, 120-129. [CrossRef]

41. Exarchou, V.; Nenadis, N.; Tsimidou, M.; Gerothanassis, I.P.; Troganis, A.; Boskou, D. Antioxidant activities and phenolic composition of extracts from Greek oregano, Greek sage, and summer savory. J. Agric. Food Chem. 2002, 50, 5294-5299. [CrossRef]

42. Cidade, H.; Rocha, V.; Palmeira, A.; Marques, C.; Tiritan, M.E.; Ferreira, H.; Lobo, J.S.; Almeida, I.F.; Sousa, M.E.; Pinto, M. In silico and in vitro antioxidant and cytotoxicity evaluation of oxygenated xanthone derivatives. Arab. J. Chem. 2020, 13, 17-26. [CrossRef]

43. Martins, N.; Barros, L.; Duenas, M.; Santos-Buelga, C.; Ferreira, I.C.F.R. Characterization of phenolic compounds and antioxidant properties of Glycyrrhiza glabra L. rhizomes and roots. RSC Adv. 2015, 5, 26991-26997. [CrossRef]

44. Re, R.; Pellegrini, N.; Proteggente, A.; Pannala, A.; Yang, M.; Rice-Evans, C. Antioxidant activity applying an improved ABTS radical cation decolorization assay. Free Radic. Biol. Med. 1999, 26, 1231-1237. [CrossRef]

45. Lúcio, M.; Nunes, C.; Gaspar, D.; Ferreira, H.; Lima, J.L.F.C.; Reis, S. Antioxidant Activity of Vitamin E and Trolox: Understanding of the Factors that Govern Lipid Peroxidation Studies In Vitro. Food Biophys. 2009, 4, 312-320. [CrossRef]

46. Dorta, E.; Fuentes-Lemus, E.; Aspée, A.; Atala, E.; Speisky, H.; Bridi, R.; Lissi, E.; López-Alarcón, C. The ORAC (oxygen radical absorbance capacity) index does not reflect the capacity of antioxidants to trap peroxyl radicals. RSC Adv. 2015, 5, 39899-39902. [CrossRef]

47. Pardau, M.D.; Pereira, A.S.P.; Apostolides, Z.; Serem, J.C.; Bester, M.J. Antioxidant and anti-inflammatory properties of Ilex guayusa tea preparations: A comparison to Camellia sinensis teas. Food Funct. 2017, 8, 4601-4610. [CrossRef] [PubMed]

48. Fernandes, E.; Costa, D.; Toste, S.A.; Lima, J.L.F.C.; Reis, S. In vitro scavenging activity for reactive oxygen and nitrogen species by nonsteroidal anti-inflammatory indole, pyrrole, and oxazole derivative drugs. Free Radic. Biol. Med. 2004, 37, 1895-1905. [CrossRef] [PubMed]

49. Feelisch, M.; Noack, E.A. Correlation between nitric oxide formation during degradation of organic nitrates and activation of guanylate cyclase. Eur. J. Pharmacol. 1987, 139, 19-30. [CrossRef]

50. Hetrick, E.M.; Schoenfisch, M.H. Analytical Chemistry of Nitric Oxide. Annu. Rev. Anal. Chem. 2009, 2, 409-433. [CrossRef]

51. Vieira, S.; Franco, A.R.; Fernandes, E.M.; Amorim, S.; Ferreira, H.; Pires, R.A.; Reis, R.L.; Martins, A.; Neves, N.M. Fish sarcoplasmic proteins as a high value marine material for wound dressing applications. Colloids Surf. B Biointerfaces 2018, 167, 310-317. [CrossRef] 
52. Lima, A.C.; Cunha, C.; Carvalho, A.; Ferreira, H.; Neves, N.M. Interleukin-6 Neutralization by Antibodies Immobilized at the Surface of Polymeric Nanoparticles as a Therapeutic Strategy for Arthritic Diseases. ACS Appl. Mater. Interfaces 2018, 10, 13839-13850. [CrossRef]

53. Bachiega, T.F.; Sforcin, J.M. Lemongrass and citral effect on cytokines production by murine macrophages. J. Ethnopharmacol. 2011, 137, 909-913. [CrossRef]

54. Brahmi, F.; Nury, T.; Debbabi, M.; Hadj-Ahmed, S.; Zarrouk, A.; Prost, M.; Madani, K.; Boulekbache-Makhlouf, L.; Lizard, G. Evaluation of Antioxidant, Anti-Inflammatory and Cytoprotective Properties of Ethanolic Mint Extracts from Algeria on 7-Ketocholesterol-Treated Murine RAW 264.7 Macrophages. Antioxidants 2018, 7, 184. [CrossRef] [PubMed]

55. Ben Farhat, M.; Jordán, M.J.; Chaouech-Hamada, R.; Landoulsi, A.; Sotomayor, J.A. Variations in Essential Oil, Phenolic Compounds, and Antioxidant Activity of Tunisian Cultivated Salvia officinalis L. J. Agric. Food Chem. 2009, 57, 10349-10356. [CrossRef] [PubMed]

56. Martins, N.; Barros, L.; Santos-Buelga, C.; Henriques, M.; Silva, S.; Ferreira, I.C.F.R. Evaluation of bioactive properties and phenolic compounds in different extracts prepared from Salvia officinalis L. Food Chem. 2015, 170, 378-385. [CrossRef] [PubMed]

57. Shan, B.; Cai, Y.Z.; Sun, M.; Corke, H. Antioxidant capacity of 26 spice extracts and characterization of their phenolic constituents. J. Agric. Food Chem. 2005, 53, 7749-7759. [CrossRef]

58. Cuvelier, M.E.; Berset, C.; Richard, H. Antioxidant Constituents in Sage (Salvia officinalis). J. Agric. Food Chem. 1994, 42, 665-669. [CrossRef]

59. Sallam, A.; Mira, A.; Ashour, A.; Shimizu, K. Acetylcholine esterase inhibitors and melanin synthesis inhibitors from Salvia officinalis. Phytomedicine 2016, 23, 1005-1011. [CrossRef]

60. Maksimovic, S.; Kesic, Z.; Lukic, I.; Milovanovic, S.; Ristic, M.; Skala, D. Supercritical fluid extraction of curry flowers, sage leaves, and their mixture. J. Supercrit. Fluids 2013, 84, 1-12. [CrossRef]

61. Radulescu, V.; Chiliment, S.; Oprea, E. Capillary gas chromatography-mass spectrometry of volatile and semi-volatile compounds of Salvia officinalis. J. Chromatogr. A 2004, 1027, 121-126. [CrossRef]

62. Lu, Y.; Foo, L.Y. Flavonoid and phenolic glycosides from Salvia officinalis. Phytochemistry 2000, 55, $263-267$. [CrossRef]

63. Roby, M.H.H.; Sarhan, M.A.; Selim, K.A.-H.; Khalel, K.I. Evaluation of antioxidant activity, total phenols and phenolic compounds in thyme (Thymus vulgaris L.), sage (Salvia officinalis L.), and marjoram (Origanum majorana L.) extracts. Ind. Crops Prod. 2013, 43, 827-831. [CrossRef]

64. Tada, M.; Hara, T.; Hara, C.; Chiba, K. A quinone methide from Salvia officinalis. Phytochemistry 1997, 45, 1475-1477. [CrossRef]

65. Durling, N.E.; Catchpole, O.J.; Grey, J.B.; Webby, R.F.; Mitchell, K.A.; Foo, L.Y.; Perry, N.B. Extraction of phenolics and essential oil from dried sage (Salvia officinalis) using ethanol-water mixtures. Food Chem. 2007, 101, 1417-1424. [CrossRef]

66. Albano, S.M.; Miguel, M.G. Biological activities of extracts of plants grown in Portugal. Ind. Crops Prod. 2011, 33, 338-343. [CrossRef]

67. Farhat, M.B.; Landoulsi, A.; Chaouch-Hamada, R.; Sotomayor, J.A.; Jordán, M.J. Characterization and quantification of phenolic compounds and antioxidant properties of Salvia species growing in different habitats. Ind. Crops Prod. 2013, 49, 904-914. [CrossRef]

68. Nanni, V.; Canuti, L.; Gismondi, A.; Canini, A. Hydroalcoholic extract of Spartium junceum L. flowers inhibits growth and melanogenesis in B16-F10 cells by inducing senescence. Phytomedicine 2018, 46, 1-10. [CrossRef]

69. Mphahlele, R.R.; Fawole, O.A.; Mokwena, L.M.; Opara, U.L. Effect of extraction method on chemical, volatile composition and antioxidant properties of pomegranate juice. S. Afr. J. Bot. 2016, 103, 135-144. [CrossRef]

70. Leelarungrayub, N.; Rattanapanone, V.; Chanarat, N.; Gebicki, J.M. Quantitative evaluation of the antioxidant properties of garlic and shallot preparations. Nutrition 2006, 22, 266-274. [CrossRef]

71. Fecka, I.; Turek, S. Determination of water-soluble polyphenolic compounds in commercial herbal teas from Lamiaceae: Peppermint, melissa, and sage. J. Agric. Food Chem. 2007, 55, 10908-10917. [CrossRef]

72. Jesionek, W.; Majer-Dziedzic, B.; Choma, I.M. Separation, Identification, and Investigation of Antioxidant Ability of Plant Extract Components Using TLC, LC-MS, and TLC-DPPH•. J. Liq. Chromatogr. Relat. Technol. 2015, 38, 1147-1153. [CrossRef] 
73. Wang, M.; Li, J.; Rangarajan, M.; Shao, Y.; LaVoie, E.J.; Huang, T.-C.; Ho, C.-T. Antioxidative Phenolic Compounds from Sage (Salvia officinalis). J. Agric. Food Chem. 1998, 46, 4869-4873. [CrossRef]

74. Lu, Y.; Yeap Foo, L. Antioxidant activities of polyphenols from sage (Salvia officinalis). Food Chem. 2001, 75, 197-202. [CrossRef]

75. Atoui, A.K.; Mansouri, A.; Boskou, G.; Kefalas, P. Tea and herbal infusions: Their antioxidant activity and phenolic profile. Food Chem. 2005, 89, 27-36. [CrossRef]

76. Kozics, K.; Klusová, V.; Srančíková, A.; Mučaji, P.; Slameňová, D.; Hunáková, L'; Kusznierewicz, B.; Horváthová, E. Effects of Salvia officinalis and Thymus vulgaris on oxidant-induced DNA damage and antioxidant status in HepG2 cells. Food Chem. 2013, 141, 2198-2206. [CrossRef]

77. Pereira, O.R.; Catarino, M.D.; Afonso, A.F.; Silva, A.M.S.; Cardoso, S.M. Salvia elegans, Salvia greggii and Salvia officinalis Decoctions: Antioxidant Activities and Inhibition of Carbohydrate and Lipid Metabolic Enzymes. Molecules 2018, 23, 3169. [CrossRef] [PubMed]

78. Kontush, A. Amyloid- $\beta$ : An antioxidant that becomes a pro-oxidant and critically contributes to Alzheimer's disease. Free Radic. Biol. Med. 2001, 31, 1120-1131. [CrossRef]

79. DeNardo, D.G.; Ruffell, B. Macrophages as regulators of tumour immunity and immunotherapy. Nat. Rev. Immunol. 2019, 19, 369-382. [CrossRef] [PubMed]

80. Kim, H.; Ban, I.; Choi, Y.; Yu, S.; Youn, S.J.; Baik, M.-Y.; Lee, H.; Kim, W. Puffing of Turmeric (Curcuma longa L.) Enhances its Anti-Inflammatory Effects by Upregulating Macrophage Oxidative Phosphorylation. Antioxidants 2020, 9, 931. [CrossRef] [PubMed]

81. Arranz, E.; Jaime, L.; Lopez de la Hazas, M.C.; Vicente, G.; Reglero, G.; Santoyo, S. Supercritical sage extracts as anti-inflammatory food ingredients. Ind. Crops Prod. 2014, 54, 159-166. [CrossRef]

82. Ma, Z.; Lu, Y.; Yang, F.; Li, S.; He, X.; Gao, Y.; Zhang, G.; Ren, E.; Wang, Y.; Kang, X. Rosmarinic acid exerts a neuroprotective effect on spinal cord injury by suppressing oxidative stress and inflammation via modulating the Nrf2/HO-1 and TLR4/NF-kB pathways. Toxicol. Appl. Pharmacol. 2020, 397, 115014. [CrossRef]

83. Xia, G.; Wang, X.; Sun, H.; Qin, Y.; Fu, M. Carnosic acid (CA) attenuates collagen-induced arthritis in db/db mice via inflammation suppression by regulating ROS-dependent p38 pathway. Free Radic. Biol. Med. 2017, 108, 418-432. [CrossRef]

84. Shi, W.; Xu, G.; Zhan, X.; Gao, Y.; Wang, Z.; Fu, S.; Qin, N.; Hou, X.; Ai, Y.; Wang, C.; et al. Carnosol inhibits inflammasome activation by directly targeting HSP90 to treat inflammasome-mediated diseases. Cell Death Dis. 2020, 11, 252. [CrossRef] [PubMed]

Publisher's Note: MDPI stays neutral with regard to jurisdictional claims in published maps and institutional affiliations.

(C) 2020 by the authors. Licensee MDPI, Basel, Switzerland. This article is an open access article distributed under the terms and conditions of the Creative Commons Attribution (CC BY) license (http://creativecommons.org/licenses/by/4.0/). 